
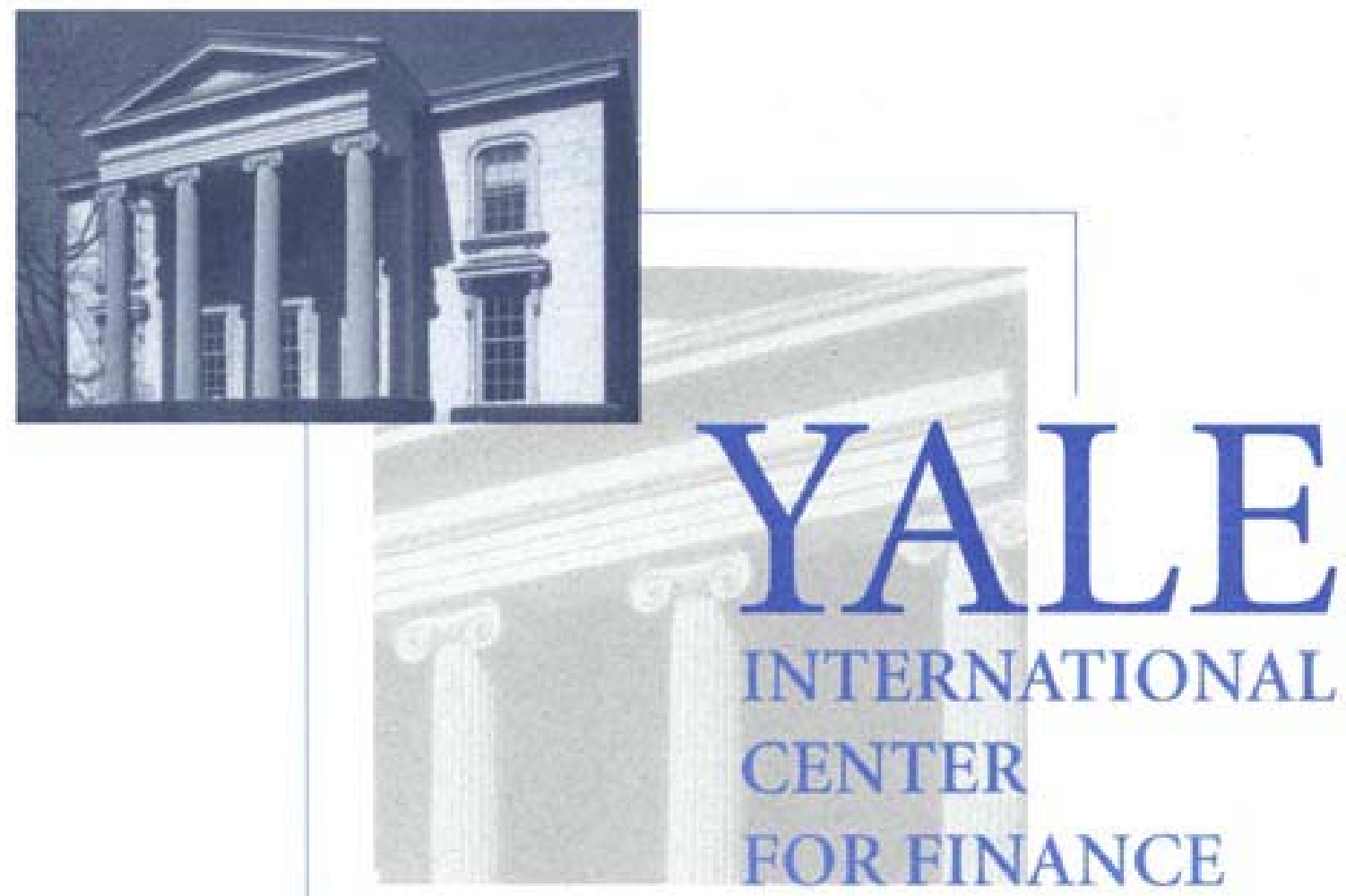

Yale ICF Working Paper No. 00-62

October 16, 2001

\title{
CHINA AND THE WORLD FINANCIAL MARKETS 1870-1930: MODERN LESSONS FROM HISTORICAL GLOBALIZATION
}

\author{
William N. Goetzmann \\ Andrey Ukhov \\ Ning Zhu \\ Yale School of Management
}




\title{
1870-1930 年间的中国与世界金融市场：
}

\section{过去的全球化经验对当前的启示}

\author{
耶鲁大学管理学院 \\ 威廉 郭志满 (William N. Goetzmann) \\ 安德雷 尤科夫 (Andrey Ukhov) \\ 朱宁 (Ning Zhu)
}

2001 年 10 月 26 日

本文回顾了世界金融市场发展一个关键时期里中国金融市场的发展, 并且以当今国际金 融市场的角度研究了中国金融市场在当时的发展。尽管今天的中国和一百年前有根本不同, 但仍然不能不考虑这种国内外投资者之间的不均衡、国内外投资者对于投资者保护预期的不 一致所引起的危险后果。上个世纪的经验表明, 今天的中国应该考虑让中国的投资者有机会 参与外国资本市场, 从而在国内外投资者之间的资产分散程度上达到平衡。此外, 对本国法 人投资者利益的保护应当至少达到对外国投资者利益保护的程度。

致谢：We thank Zhiwu Chen, Otto Lam, Sir Anthony Neoh,Hidetoshi Mine, Sayuri Shirai and Geert Rouwenhorst for helpful comments. We thank the Tokyo participants in the ADBI/Wharton Seminar on Regulatory Difference-Banking Sector Regulations and Securities Market Regulations. We also thank Mingfeng Lin for helping translate the Chinese version. For information please contact: William N. Goetzmann, International Center for Finance, Yale School of Management, 135 Prospect Street, New Haven, CT, USA 06520. E-mail: william.goetzmann@yale.edu 


\section{1、引言}

20 世纪初期, 中国作为一个新兴市场, 是全球投资的焦点地区之一。据估 计, 1938 年中国所获得的全部外国资本投资额约 25 亿美元, 作为市场开发投资 的对象, 中国仅次于印度和阿根廷而位居第三 ; 与当时美国所获得的 70 亿美元 的外国投资也相差不远 ${ }^{1}$ 。1 1860 年左右中国开始进入世界资本市场向外国投资者 借款; 1870 年左右, 中国开始尝试发行在国内发行股票; 1880 年左右, 上海已 经开始建立交易外国股票的市场。直至 1920 年, 世纪资本市场已经广泛地交易 中国发行的证券了。与此同时，上海也逐渐发展成为世界瞩目的国际金融中心。 特别引人注意的是中国资本市场和国际资本市场发展之间的不平衡。尽管中国在 上个世纪之交尝试通过建立股份公司筹集资本, 但直到清朝统治结束, 中国仍很 大程度上依靠国外投资。尽管外国投资为中国的发展筹措了资金, 然而为吸引他 们投资于这个危险的新兴市场的保护外国投资者的力量, 也使得这个国家几乎陷 于分崩离析的境地。从外国人的角度来看, 对于投资者的保护似乎已经是合理的 - 一欧洲市场上知名投资银行发行的中国政府债券都以中国政府的财政收入为 抵押, 而且这些收入正是由欧洲人来收取和监督的。相似的, 中国的铁路债券也 以铁路财产和收入为担保。虽然这些铁路名义上属于中国所有, 但却是由建设这 些铁路的企业中的外国代表来运营的。从中国人的角度来看, 这些情况却是对中 国主权的侵犯和对本国企业部门发展的阻碍。因此, 中国国外融资的这些条件, 就直接导致了国人对外国人占有中国资本以及外国人蚌食中国主权的强烈反对。

19 世纪末外国投资导致中国国家主权弱化, 这使得这个世界上人口最多的 国家失去了一次融入当时正强劲增长的全球经济体之中的机会。相反, 中国军划 时代的政治分裂局面以及随之而来反对日本殖民主义的长期战争, 加上反对帝国 主义的斗争，都把中国同世界共同体之间广泛的经济和金融联系逐步疏远。

在本文中，我们将考察这个时期中是什么导致了对外国资本的严重依赖，同 时也将考察外国投资者所要求的严苛的贷款条件背后的经济动因。我们相信，在 这两个因素的背后, 都有着很强的金融上的驱动力量。虽然 19 世纪末西方列强

\footnotetext{
${ }^{1}$ Lewis, Cleora, 1948, The United States and Foreign Investment Problems, The Brookings Institution, Washington. P. 295.
} 
对中国的准殖民化更多地被看作一种政治过程, 我们认为, 基础的金融因素在其 中也起到了重要作用。这些金融方面的因素, 即使是中国在 21 世纪的今天雄心 勃勃地进军世界金融市场的时候, 可能仍然非常重要。中国今天所面临的问题与 一个世纪前所遇到的问题, 具有某种程度的相似性。其中包括: 对促进发展的基 础设施建设的持续要求、加入 WTO 带来的外国资本投资和外国竞争的潜在可能 性、以及如何最好地动员国内储蓄的问题。为了让读者对于我们的研究结论首先 有一个大致的了解, 我们认为: 一个世纪之前中国对外举债所带来的一些严重政 治后果, 很大程度上可以归因于两个金融上的因素。这两个因素是随着 19 世纪 欧洲资本市场的迅速发展而产生的。第一个因素是国际投资者机会集合与中国投 资机会集合之间的巨大不均衡。100 年之前, 欧洲具有世界上流动性最高的、发 展最为完善的资本市场。资本市场为欧洲工业的发展提供了强有力的推动力量, 也为技术创新提供了一个流动性很好的筹资渠道。从供给面来看, 欧洲资本市场 不仅仅动员了富有的大投资者的储蓄, 同时也利用了中等水平储蓄者的投资能 力。

19 世纪在上海、香港等金融中心，或许确实存在小规模的资本市场，但这 些地方同伦敦、巴黎和阿姆斯特丹等地的国际资本市场却不能同日而语。这种差 异性的存在为欧洲企业提供了根本性的相对优势一一它可以很方便地利用投资 来开发象铁路这样大规模的资本密集型工程。与其他国家那些仅仅限于本国证券 的市场相比, 欧洲资本市场的一个尤为重要的特点在于: 小规模的投资者也可以 持有分散化的资产组合。金融理论中，这种分散性方面的非均衡性表明，外国投 资者事实上可能是中国企业债券和政府公债的边际投资者。换而言之, 如果外国 和中国资本家为争夺商业项目而短兵相接, 外国投资者因为资产较为分散而享有 较低的资本成本, 从而能够支付更多的资本投入。

在中国的外债逐步加重过程之中存在的第二个因素是中国法律保护和企业 治理结构的不成熟。在 19 世纪末, 许多欧洲国家都已经对商业企业的范畴和治 理问题形成了一定的法律和规定，同时也对企业债务和政府债务证券持有者的权 利提供了法律保护。在亚洲, 日本很快效仿欧洲, 采用了相似的金融市场和结构 
形式, 而在中国, 直到 20 世纪初这方面才有了明显的行动。即使是这个时候, 许多地方绅士和地方政府官员, 对商业企业的经营仍然具有相当大的影响。20 世纪之前, 中国的铁路和矿厂几乎全部都是欧洲企业的子公司, 而不是中国企业 的子公司。这些外国特权者从清政府获得了种种担保, 如可以直接控制收入; 有 权在债务、未获清偿时直接取得财产; 有权自主获得生产所需的原材料; 并且有 权免于国内外的竞争。在某些情况下, 这类特许权几乎达到完全脱离中国法律和 税收、脱离当地竞争的程度。外国公司甚至甚至可以发行单独的货币。这些交易 虽然降低了外国投资者的风险, 但却让外国企业比中国企业享有越来越多的保 护，从而导致对中国主权的削弱。

那些投资于中国政府债券的外国投资者们所得到的保护则更为惊人。从 19 世纪中期开始, 中国海关的关税收入就是由英国人来收取和控制的。这样, 在这 些海关关税收入进入中国国库之前, 英国就可以被直接用其支付外债。这事实上 给予债券持有人的是对中国主要财政收入来源的第一索取权。的确, 这种做法降 低了中国不偿还债务的可能, 从而降低了中国政府融资的成本; 但也同时限制了 中国政府的运用自己财政资金的能力, 把中国政府的钱包放到了外国力量的手 中。

外国对中国海关关税的控制以及中国政府对外国人给予的优惠商业政策, 也 许起初有助于控制外国投资者面临的风险，但这些做法导致了严重的政治后果。 事实上, 不论是当时还是现在, 这些都被认为是非常危险的做法, 甚至可能成为 外国对中国实行殖民化的中间步骤 2 。外国对中国交通运输系统和贸易收入的控 制，使清政府处于外国力量要求领土权利的政治压力之下。英国、法国、德国、 俄国和日本等西方列强都对中国领土虎视䀓䀓。或许投资者的利益确实是给予商 业及政府特权的初始动因, 但中日甲午战争之后, 不管中国是否确实有借款的需 要, 西方列强都会为争夺中国铁路开发融资权而你争我斗。20世纪初, 中国政 府由于要支付这些国家强加的战争赔款而债台高筑一一而这又使得外国在要求 扩大势力范围的谈判中有了更多的砝码。西方列强对中国政府的压力, 加上中国

\footnotetext{
${ }^{2}$ See, for example, Winston, A. P., 1916, "Chinese Finance Under the Republic," Quarterly Journal of Economics, 30(4) August, 738-779.
} 
金融市场与发达世界金融市场的制度性非均衡, 共同产生了非常严重的后果: 最 终导致外国人占有中国的生产资本, 外国资本家在中国自行其是, 同时也逐步导 致清政府对中国领土的控制渐趋弱化。

本文余下部分的组织如下: 在下两部分, 我们将以当今全球金融体系的角度 分析中国早期股票和债券市场的发展。第四部分着重考察中国当时的铁路债券。 第五部分探讨了中国资本市场发展历史中投资组合分散化和公司治理结构的问 题。第六部分总结全文, 并对当前中国资本市场发展的现状作出一定的建议。 


\section{I. 股票市场的发展}

\section{1 国际股票市场的发展}

1911 年 Rudolph Taüber 对世界股票市场的考察为第一次世界大战之前国际 投资的形势提供了一个很好的概览。他描述了德国投资者所能够进入的三十多个 国家的证券交易所的情况 ${ }^{3}$ 。英国作家 Henry Lowenfeld 在他 1909 年出版的《投 资学———门精确的科学》中, 列举了英国投资者能够进入的存在证券交易市场 的 40 个国家 ${ }^{4}$ 。事实上, 对于那个时期的英国投资者来说, 他们只需在伦敦股票 交易所进行交易，就可以进入这些市场一一他们可以购买那些在伦敦上市的外国 企业的股份和股票，也可以购买已经获得特许权、可以在海外开展业务的英国企 业的证券。Lowenfeld 的研究之所以特别令人感兴趣, 使因为他提出了一种基于 “资本地理分布” 的国际分散化策略。通过用大量的图形来表明不同国家证券行 情运动的不相关性, 他认为, 要获得良好的投资成果, 投资者应当将资本以相应 的比例在一系列地理位置上均匀分布，并且每个一段时间就要调整投资组合，严 格地回复到这些比例上来。

这里非常重要的一点就是要考察“按地理分布的股票”中剩下的全 部股票的价格运动如何不同于英国股票。正是这种包括在一个良好 的投资分散组合这种的每一支证券运动的独立性，才奠定了成功投 资活动的最重要的基础, 也就是 “资本稳定化” 5 。

很明显, 在上个世纪之交的时候, 这种地理分散化的投资策略在英国以及其 他欧洲国家的投资者中非常流行。欧洲一直是世界的主要资本输出国，直到第一 次世界大战结束之后，美国和日本作为国际债权人的地位才变得突出。Michael Edelstein 根据各国在 1881 年到 1913 年间各个 5 年期之中资本流出的情况, 将英 国、法国和德国列为主要债权国 ; 这个时期中，俄国、挪威、澳大利亚、南非和

\footnotetext{
${ }^{3}$ These include Germany, Austria, Switzerland, the Netherlands, Norway, Sweden, Denmark, Russia, Serbia, Greece, Rumania, Turkey, Italy, Spain, Portugal, Belgium, France, Great Britain, Ireland, New York, Haiti, Dominican Republic, Ecuador, Brasil, Peru, Argentina, Uruguay, Chile, Columbia, Venezuela, Japan, South Africa, Natal, Egypt and Australia.

${ }^{4}$ Great Britain, India, Canada, Australia, Tasmania, New Zealand, Straits Settlements (Singapore), Belgium, Denmark, Germany, Holland, Norway, Russia, Sweden, Switzerland, Austria, Bulgaria, France, Greece, Italy, Hungary, Portugal, Roumania, Spain, Serbia, Turkey, Japan (Tokio and Yokohama), China (Shanghai and Hong Kong), Cape Colony, Natal, Transvaal, Egypt, New York, Mexico, Argentine, Brazil, Chile, Peru and Uruguay. ${ }^{5}$ Lowenfeld, Henry, 1909, Investment an Exact Science, The Financial Review of Reviews, London. p. 49.
} 
美国在某些时候也成为地位稍逊一些的资本输出国 ${ }^{6}$ 。Cleora Lewis 对国际资本流 动作了一个全面的研究, 认为截止到 1938 年, 美国、英国、荷兰、比利时、瑞 典、意大利和日本是世界上仅有的资本输出国 ${ }^{7}$ 。当然, 这并不表明所有非资本 输出国的投资者们都没有实现分散化。根据例如 “资本资产定价模型” 这样的均 衡模型的结论，如果所有的投资者都持有相同的风险资产组合，小国的投资者们 所持有的将大部分都是外国的资产; 由于同样的原因，小国的企业的投资者也将 大部分来自于外国。

\section{II.2 中国股票市场的发展}

和美国及日本形成鲜明对比, 19 世纪中国资本市场的发展是有限的。这一方 面表现在国内投资者的投资机会有限: 投资者在地域上局限于东南沿海。另一发 面, 早期市场的激烈波动更是阻碍了资本市场的广泛发展。尽管如此, 中国早期 债权和股权市场的发展仍然一定程度上解释了国内外投资者之间的差异。

中国早期资本市场的发展一定程度上源于在海外留学的中国学者。知名的改 革者, 耶鲁大学 1854 年毕业生容阉, 曾于 1867 年向江苏提督建议组建合资铁路 公司。虽然他的计划得以采纳, 但是直到 1872 年, 上海企业家盛宣怀才建立了 合资公司---轮船招商局和外国航运公司竞争。在 19 世纪 70 至 80 年代, 在’官督

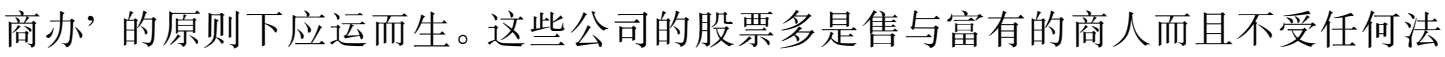
律监管。这类官督商办企业的股份很少交易。19 世纪 80 年代, 上海的中文报纸 (申报)已经开始刊登这些股票的价格, 但是那时还没有正式的股票交易所。

中国历史上第一次股价高涨出现在 19 世纪 80 年代。当时”上市”公司的数 量从 10 家增加到 29 家，有些股价自 1882 年中至 1884 年止上涨了超过 4 倍，满 足了投机者的需要。可惜股价自 1884 年起开始下跌, 至 1887 年止, 大多数公司 的股价跌至了股票面值的一半, ”上市” 公司的数目也降至了 12 家。股家暴跌之 后，申报不再刊登股票价格。19 世纪 80 年代股价的暴跌对此后 20 多年股市的

\footnotetext{
${ }^{6}$ Edelstein, Michael, 1982, Overseas Investment in the Age of High Imperialism, Methuen and Co. New York, p.
} 271. 
沉寂负有一定责任。

1891 年, 驻上海的外国商人在上海开设了中国第一家股票交易所, 上海股票 交易所。通过和其他交易所的合并，它逐渐发展成为” 众业公所”。众业公所 起初只交易外国公司的股票。虽然这有助于外国商人进行国际风险分散，但她对 于中国国内投资者的好处却并不明显。只有会员才能在”众业公所”交易, 而在 当时 100 名会员中, 中国人只占 10 个席位左右。正如外国商人在华设置的其他 限制一样, 直到 1935 年, 中国人始终不能自由地在”众业公所” 进行交易。国 内公司的股票仍然只在交易所外交易。1918 年, 专门交易国内股票的北京中国 股票交易所正式建立。而当时影响最大的上海华商股票交易所则是在 1920 年建 立的。

中国的第二次股市危机出现在 1910 年。有些外国公司号称在东南亚拥有当 时非常重要的橡胶种植园。中国的金融机构和个人投资者投入了多于 6 千万两白 银的资本投机于股票市场。随着国际橡胶市场价格的下跌和一些外国公司的消 失, 股价大幅下跌。由于当时没有相应措施管制银行和钱庄, 许多金融机构都通 过不同途径掌握大量橡胶股票。股价的大幅下跌使得一半以上的钱庄不得不宣布 破产。我们以为, 如果当时中国存在对公司和金融机构的公布和监管政策, 那么 这场危机可能是可以避免的。

即使在中华民国建立之后，证券监管仍然不很有效。虽然中华民国政府在 1914 年颁布了有关证券交易的法律，这些法律没有得到有效地执行。尽管上市 公司的运行已经接近西方当代上市公司的水平, 证券交易所没有得到应有的监督 和管理。20 世纪 20 年代初, 现有股票交易所的高额利润吸引了众多集体和个人 投资开设交易所。以为当时没有法令对建立交易所提出要求, 上海一时间出现了 上百家不同的交易所。在短短两年内, 只有 6 家交易所幸存下来。为了恢复投资 者的信心，上海华商交易所对其会员提出了更严格的要求。

\footnotetext{
${ }^{7}$ Lewis, Op. Cit.
} 
截止 1935 年，上海华商交易所逐步发展成为远东地区最大的交易所之一。 上海华商交易所交易大约 190 种股票，年均交易额大约 2 万亿至 5 万亿元。特别 值得一提的是上海华商交易所自身也是一家上市公司。上海发展成为亚洲最重要 的资本市场之一。这和 30 年前的情形大相径庭。当时虽然外国商人控制的交易 所得以发展，但国内企业仍然很难筹到资金而国内投资者的投资组合也不尽分 散。作为结果, 上个世纪之交的中国资本市场从规模而言, 和欧洲和日本的资本 市场都相去甚远。

\section{II.3 资本市场的发展与改革}

有研究表明中国在明朝中页就在采矿业和制造业出现了资本主义萌芽。这些 早期资本主义发展通过在通商口岸和西方的接触, 获得了飞速发展的机会。在给 中国带来的种种负面影响的前提下，西方诸强在 18 世纪对中国的入侵从一定程 度上为中国国内制造业的发展创造了机会。欧洲诸强在的金融机构在各通商口岸 的成功一定程度上引发了中国自身金融系统的发展。

1904 年, 为了便利国内企业的发展, 同时限制外国股东和债权人对控制权 的掌握, 中国政府的商务部门针对商业法令推行了一系列的改革, 并于 1905 年 进一步制定了破产法。根据一项估计，从 1903 年到 1908 年，上述努力为中国 265 家新企业吸引到了约一亿三千万两白银(约合一亿美元)的资金8。这些新企业 之中的 10 家是铁路公司, 在中国 1904 年公司法案之后注册的企业总资本中, 这 些公司的资本额就占了将近一半。除根据正式法令成立的公司之外, 为了向铁路 建设提供资金并直接与国外特许权人竞争，当时还出现了相当多其他形式的组 织。表一(取自 Lee，1977)列出了 1903 年到 1909 年间成立的 19 家铁路公司, 其 中有许多得到了地方政府的正式补贴; 这些补贴来自于政府对大米、鸦片、鸦片 烟斗、海盐、彩票、木材、邮票、房租、官员薪水和土地所征税收。如表所示, 这些投资能保证的回报率并不高一一大约在 $4 \%$ 到 $7 \%$ 之间; 当然, 我们并不清 楚这其中是否包括资本增值的可能，因为不论是股权还是债权，这种证券形式都

\footnotetext{
${ }^{8}$ Lee, En-Han, 1977, China's Quest for Railway Autonomy: 1904-1911, Singapore University Press, Singapore, 1977. P. 268.
} 
还没有得到认可。我们所确知的是, 筹资的目的并没有达到。虽然政府对这其中 的许多企业提供了补贴, 实际上筹集到的资金尚不足实际所需数额的一半。这是 不是因私人资本的短缺呢? 似乎不太可能。20 世纪 30 年代对中国国内财富的预 计, 和中国许多公民的主要个人财富的统计, 都表明中国有相当的能力在国内为 自己的国防力量和基础设施建设筹资。显然, 问题在于中国缺少对于股票发行和 债券承销过程的经验, 而欧洲市场对此则早已掌握9。

另一个问题在于公司治理。虽然中国政府进行了法制改革, 也采取措施规范 本国企业, 但事实表明, 1904 年改革之后成立的许多新企业, 缺乏必需的治理 结构和管理技能, 也缺乏应有的相对于政府控制的独立性, 从而使他们无法同外 国企业有效竞争。Lee 通过对这个时期中国特许经营的铁路企业的研究, 将它们 失败的原因归结为以下几个方面：(1)由于存在其他资本用途而导致的资本化程 度低下; (2)工程、技术和技能缺乏; (3)管理技能缺乏; (4)官员腐败, 营私舞弊 ${ }^{10}$ 。 当然, 第一个原因即资本化程度低下, 是问题的表现, 而不是原因。中国人之所 以不愿意投资, 既可能是由于这将与那些能够在国际间分散资本组合的外国投资 者产生竞争, 也可能是由于投资者对于企业治理问题的理性预期, 或者是二者兼 而有之。在下文我们对铁路融资的讨论中, 我们将具体分析一家具有特殊重要性 的企业。

\section{III. 政府债券市场的发展}

在表格 I 中, 我们列举了 Kuhlmann(1983)和 Stanley(1970)书中所列出的中国 外债，并根据各项贷款的抵押对它们进行编号 ${ }^{11}$ 。19 世纪末到 20 世纪初的外债 基本上都以名目繁多的政府税收为抵押，包括中国的海关关税、盐税、国内过境 税(厘金)、采矿税、烟酒税、鸦片税、财产转让税和铁路税。当然, 这些税收的 核定和征收是贷款合同的一个重要部分。中国政府最主要的税收来源之一-一海

\footnotetext{
${ }^{9}$ For macroeconomic estimates of savings capacity, see Riskin, Carl (1975). For a discussion of personal fortunes see Huenemann (1982) p. 126.

${ }^{10}$ Lee, Ibid. p. 132-141.

11 Stanley, John C. Late Ch'ing Finance: Hu Kuang-Yung as an Innovator, Cambridge, Massachusetts, 1970.
} 
关关税一一就是由外国政府在中国的主要通商口岸直接收取 ${ }^{12}$ 。虽然海关关税是 19 世纪中叶英国殖民主义的产物, 但到 20 世纪初, 它已经成为中国政府为国防 和战争赔款筹措资金的最主要来源。

\section{III.1. 国际政府债券及其回报}

在中央政府的准许下, 中国各省政府最早向外国商人借款是在 1861 年太平 天国战争期间, 随后是在 1862 年福建、台湾剿匪的时候。1 867 年和 1868 年, 为镇压中国西部穆斯林的叛乱, 中国的地方政府再次向外国举借商业借款。这些 地方贷款均以地方政府在海关关税中的份额作为抵押。1874 年, 为打破日本侵 略台湾的野心, 中国政府再次举债; 此次债务也以海关关税为抵押。19世纪 80 年代, 为了筹措资金同法国作战, 中国政府在伦敦发行了利率为 $7 \%$ 的 150 万英 镑公债, 同样以海关关税为抵押。中国政府在 1894 年到 1895 年的甲午战争中所 举借的所有外债以及随后的战争赔款, 都以海关关税为抵押; 庚子赔款-一即西 方列强在义和团起义之后强加给中国的赔款一一也是如此。数额达六亿七千五百 万的庚子赔款在 14 个列强之间瓜分, 其中有大约 $75 \%$ 流入俄国、德国、法国和 英国手中。这就从事实上把中国海关关税中以前尚未抵押的部分也交给了西方国 家, 而进口税收则尽数落入外国手中。

1900 年之后, 由于中国的关税几乎全部被用于抵押, 所以政府不得不为大额 贷款寻找新的抵押品。晚清政府的最后一些外债，如 1910 年在法国和比利时发 行的 Kiagnan 债券, 就是用盐税抵押的。1911 年, 清政府垮台, 而西方列强承 认中华民国政府的条件, 就是它必须承担清政府所欠外债。这样在 1912 年, 中 华民国的第一项主要外债, 由新的政治领导着孙中山和袁世凯参与谈判并准许发 行的 5\%的 Crisp Gold 债券, 就明确规定以盐税为抵押。1911 年、1917 年、1918 年、1922 年以及 1937 年的中国政府数次更迭，然而都采用了以盐税作为贷款抵 押的做法。从太平天国战争之后, 中国出现了内部过境税, 又称 “厘金”。在

\footnotetext{
${ }^{12}$ C.f. Stanley, page 82. The foreign oversight of Chinese maritime customs revenues began as a method for the British and French to collect their war indemnity of 8 million silver taels from China. $40 \%$ of custom revenues were paid directly to Britain and France in equal share from collections in all open ports, until the completion of the obligation in 1866 . From that point on, the $40 \%$ share was paid directly to the Imperial Government in
} 
1898 年、1909 年、1911 年和 1912 年中国政府举借外债的时候, 就是用这一税 收作为抵押物。为什么投资者对以税收作为抵押如此重视? 因为对于外国投资者 来说, 税收能带给他们安全感。在我们所研究的这段时间里, 中国内外交患, 战 火不息, 到 19 世纪末, 清政府的苸弱已是世人皆知。因此, 如果没有这样的抵 押，即使只是“临时”借款，清政府的偿付承诺也不足以兄现。

在我们研究的这段时期中, 中国债券最突出的特点可能就在于直到 1918 年, 这些债券的回报率都非常稳定。图 2 表示的是这一时期中国、印度、日本和俄国 债券收益的时间序列。对于中国来说，这段时间在政治上方面一片混乱：其间发 生了两次对外战争、义和团运动、战败赔款, 以及将清政府推向覆灭和促使中国 退出世界大战的革命。尽管发生了这些事件, 但中国债券的收益率的变动在 1899-1913 年之间从未超越 5 1 $\frac{1}{2} \%$ 到 6\%之间的狭小范围，在 1913-1918 年之间也 从未超越 6\%-7\%的范围。该表中的事件序列的数字来自于《全球金融数据库》。 它采用的是在《经济学家》杂志每个月出版的《每月投资者手册》上记录的伦敦 股票市场上中国政府债券的收益序列。涉及的债券有 1874 年台湾战争的年率为 $8 \%$ 的债券, Baring Brothers 于 1885 年在伦敦承销发行的年率为 $6 \%$ 的英镑贷款， 以及 1912-1913 年间在伦敦、巴黎、法兰克福和圣彼得堡发行的年率为 5\%的重 组贷款。上述贷款中的前两项是用海关关税凭证来抵押的, 第三项则是中国政府 的直接债务, 并以盐税和海关关税盈余为担保。

考虑到欧洲和美国的证券在对战争期间波动剧烈，中国债券回报率的稳定性 显得尤为引人注目了。第一次世界大战期间的欧洲债券市场随着参战国战争财富 的增减而波动，而第二次世界大战期间的欧洲股票市场则反映了参战国的相对强 弱 $^{13}$ 。对于美国内战的研究表明, 金融市场的走势能够反映出一一某些时候甚至 超前于一一主要战斗的结果 ${ }^{14}$ 。市场之所以会对某些重要的政治事件做出反应, 其基本原理在于一个假设: 当某些政治上、军事上的事件影响到证券发行方的时

\footnotetext{
Peking, who found it convenient to maintain the same structure and oversight of the customs duties.

${ }^{13}$ For yield fluctuations in Europe during World Wars, see Fergusen, Niall, 2000, The Cash Nexus, Basic Books, New York. For equity fluctuations during World War II see Jorion and Goetzmann, 1999, "Global Stock Markets of the 20 ${ }^{\text {th }}$ Century," Journal of Finance 54(3) 953-980.

${ }^{14}$ See Roll, Richard, 1972. "Interest Rates and Price Expectations during the Civil War," Journal of Economic History :476-498 and Kristen L. Willard, Timothy W. Guinnane, Harvey S. Rosen, “ Turning Points in the Civil War: Views from the Greenback Market,” NBER Working Paper No. W5381, October 1996
} 
候, 证券得到偿付的可能性也将随之变化。反过来说, 如果对外国股票持有者的 保护非常有效, 那么我们可以预料, 政治事件的出现将不会引起证券价格的波动。

我们对中国的债券价格反映所考察的第一个政治时间是 1894-1895 年的中日 战争以及随后关于战争赔款的的谈判。在 1895 年初, 关于条约的种种传言以及 可能的赔偿情况, 基本上应该能够在价格上反映出来了; 在 1895 年 4 月 17 日之 后, 两亿两白银的战败赔偿的消息已经基本上流传开 $3^{15}$; 令人惊讶的是一一如 果说确实有什么反应的话-一虽然 1895 年为偿付战争赔款而发行的 $6 \%$ 的债券 同样也主要以海关关税为抵押, 但是在战争期间, 年率为 $8 \%$ 的财政债券的价格 反而出现了下降。

我们要考察的关于中国政府违约风险提高而影响债券收益率的第二个时间 是 1901 年, 即清政府为偿付庚子赔款融资的时候。此次融资未采取债券形式, 而是让西方国家㩲取了中国政府手中仅存的海关关税收入的绝大部分; 到一战结 束时, 各国有的推迟了偿付时间, 有的则废除了赔款。庚子赔款的受偿国对于中 国海关关税收入只有位次较低的索取权, 和其他债务相比不具有优先权 ${ }^{16}$ 。尽管 如此, 对清政府来说, 这仍然是一个沉重的经济负担, 并且, 直接的债权人不是 在清政府违约时只能寻求法律保护的债券持有人, 而是拥有军队的他国政府。因 此，假如清政府确实发生了财政危机，在偿付的优先顺序上是否真的能够严格依 从约定, 就很难说了。作为结果, 虽然这些事件在历史上很重要, 伦敦市场的中 国债券价格并没有对此做出什么反应。

可能导致中国政府国家债务出现违约情况的第三个事件一一或许是最重要 的事件一一是 1911 年 10 月的辛亥革命。我们可以很自然地认为，那些持有清政 府债权的投资者得知清政府已经被武力推翻, 代之而起的是一位深受民众推崇的 军事强人之时, 当然会非常担心。然而我们再次发现, 尽管当时新政府急需获 取国内各界的支持，伦敦市场上债券价格的变动却没有对这种不确定性做出反 映：国外投资者并不担心中国新政府会拒付她的债务。

\footnotetext{
${ }^{15}$ For details of the treaty negotiations see Beasley, W.G., Japanese Imperialism 1894-1945, Clarendon Press, 1987, p. 64.
} 
西方列强承认中国新政府的条件是它必须承继清政府的各项外债。作为实现 这一目标的第一步, 中国的新领导人袁世凯于 1913 年与英国、德国、法国、俄 国、比利时和日本谈判, 达成了价值 2500 万英镑的重组贷款协议。美国由于认 为这一协议干涉了中国的主权, 因此没有参与这个协议。事实上该协议禁止中国 将借款用于防备俄国和日本对满洲里的侵略企图 ${ }^{17}$ 。在重组贷款中, 政治势力其 实是直接和金融势力联系在一起的; 而美国在这一复杂的谈判过程中的种种努 力, 也由于缺少外国政府证券的交易市场而受到中国羁绊。直到第一次世界大战 结束时, 由于英国的战时金融危机导致了世界金融市场的 “真空” 状态, 美国才 在这一领域取得了突出地位 ${ }^{18}$ 。到重组贷款协议得以通过并于 1913 年开始发行 的时候, 中国政府已经陷入严重的经济危机, 亟需资金以偿还中央和地方政府的 到期债务, 并支付新政府的军费和行政费用。当然, 借款所得中有一部分被用于 驻扎在北京的效忠于袁世凯的军队; 现代一些学者则认为, 这些军费中有相当部 分流入某些高级官员手中 ${ }^{19}$ 。

重组贷款标志着新政府融资活动的开始，同时也标志着中国债券高回报率、 高波动时期的开始。直到 1919 年, 借款利率平均超 1 过 6\%。历史记录显示, 从 1919 年开始, 中国陷于 “军划混战” 局面, 民国分裂为相互征战的地方性力量, 军划之间彼此间合纵连横，经济地位也时起时落。实际上，在中国债券收益的时 间序列上, 如果说中国的政治事件对于偿付债券持有人确实有影响的话, 那么这 里就是第一个证据。在此以前, 不论是在伦敦还是欧洲的其他地方, 投资者们显 然都相信, 无论中国国内如何动荡, 都已经有固定机制来防止政府没收财产的情 形。

1921 年 10 月 19 日，中国政府宣布破产; 除少数例外之外，中国开始拒付 20 年代到期的外债。只有那些直接由海关关税抵押的债券, 包括 1898 年英德贷 款和 1913 年重组贷款等, 才得以继续偿付。有意思的是, 表 1 同样也清楚地表 明了中国债务的来源情况。第一次世界大战之后, 可以很明显地看出, 由于欧洲

\footnotetext{
${ }^{16}$ Kulhmann, p.34.

17 Scholes, Walter V. and Marie V. Scholes, the Foreign Policies of the Taft Administration, Missouri Press, 1970, p. 237 and ff.

18 Atkin, John Michael, British Overseas Investment, Arno Press, 1977, p.23 and ff.
} 
和俄国资本市场的疲软，日本作为中国债权国的地位上升。

到 1939 年, 中国基本上对所有的外债都未能偿付 ${ }^{20}$ 。通常认为, 中国偿债 能力之所以下降, 是由于那种债权人直接截流关税的机制已被破坏: 内战时期, 地方军阀为筹措军事资金直接箱取税收收入的情况已司空见惯。最后, 全球范围 内经济出现衰退, 白银贬值, 加上自然灾害的影响, 使得中国已经彻底无法举借 外债。

\section{2 国内政府证券及其回报}

和清朝政府不同，中华民国政府建立之后很快开始举借内债。1914 年，民国 政府专门设立了”内国公债局”，专门负责国内公债的发行。”内国公债局” 主 要由外国人把持, 制定中国政府内债发行的计划。当时中国内债存在的最大的问 题在于内债往往没有足够的抵押--外国投资者比本国投资者享有优先受偿权。许 多内债都是以海关关税余额作为抵押的, 而海关关税的大部则已经作为先前外债 的抵押控制在外国人手中。这种抵押不足的情形最终把民国政府推到了破产的边 缘。20世纪 20 年代, 民国政府在内债和外债上违约, 不得不重组它的债务。

南京政府控制了全国后, 内债发行的规模继续上升, 以至于 1929 年, 内债 再度违约。新的一轮重组将绝大多数内债的回报率面值从百分之 7-8 下调至百分 之 6 并且将还本年限延长到原来的一倍。1929 年重组之后不久, 内债发行的规 模再度加大, 以至于民国政府于 1935 年再度违约。1936 年, 民国政府发行了价 值 2 万亿的内债以重组原有内债, 这是一年里内债发行额最高的一次。

1937 年抗日战争爆发后, 南京政府又先后发行了名目繁多的各种内债。内债 的发行不再主要面向个人投资者而是主要面向银行。除了常规发行的内债外, 南 京政府还发行了谷物和麦子为面值的债务。由于常规税收和关税收入因战事锐 减，这期间发行的债务持有人面临者更大的违约风险。

${ }^{19}$ Kulhmann, p. 87.

${ }^{20}$ Kuhlmann, p. 5. 
不断扩大的内债发行置内债持有人于更大的风险之中。两次重组下调了内债 的名义回报率并且延长了债务清偿期限。国内投资者所面临的另一种风险是通货 膨胀。20 世纪 40 年代的恶性通货膨胀使得内债持有人的内债不值原先价值的十 分之一。1948 年的币值改革更是以 3 百万比 1 的比率发行金圆券。这种恶性通 货膨胀抹去了南京政府绝大多数的内债。

总而言之, 从 19 世纪末到 20 世纪初的将近 60 年的时间里, 中国政府的负 债情况可以被划分为两个阶段: 第一个阶段是金融上的稳定时期; 第二个阶段则 是动荡时期。有意思的是, 中国政府债务偿付的稳定时期, 却恰恰是其政治上动 荡不安的时期。虽然甲午战争赔款和庚子赔款数额巨大, 但是在 10 多年的时间 里, 中国仍然能够偿付到期外债。当然, 这并非中国政府自身的选择而是由于外 国对中国政府财政收入的控制, 20 世纪初中国债券价格的稳定几乎是理所当然 的。或许可以认为, 对于外国债券持有人来说, 外国力量对中国税收的控制至少 在短期内是有利的。但是对新生的中华民国来说, 这种控制的长期影响确非常不 利 : 尽管有第一次重组贷款, 其中华民国的军费仍非常短缺。有趣的是, 中国海 关关税的透明性和可靠性一方面保证了债券持有者的安全, 而另一方面又同样使 中央政府无法获取所需资金。因此, 虽然中国的融资成本的确很低, 但这似乎不 是一桩划算的交易。

将中国的情况与亚洲其他国家债务的波动情况作一对比, 我们可以得到不少 收获。图 2 表示的是, 在 1912 年之前, 中国债券收益的稳定性非常不同寻常。 例如, 俄国债券的收益呈大幅度的波动情况, 在 19 世纪 90 年代处于低谷, 而随 俄国在日俄战争中失败之后, 又进入高峰期。日本债券的收益率原本高于中国, 但在 19 世纪 90 年代同中国签订协议之后则大幅下跌。在日俄战争之前, 日本的 债券收益率再次上升, 而日本在战争中获胜之后, 收益率又下降。这个时期中, 甚至连印度一一在英国统治下发展得相当好的殖民地一一其债券收益率的波动 情况也大于中国。我们从这些比较动态中作出的结论是: 中国政府借款的特殊性 - - 尤其是其强化的安全特征一一对保护投资者免于风险起到了一定作用。 


\section{$I V$. 铁路贷款}

关于 19 世纪末 20 世纪初全世界铁路融资的讨论, 已经很多了。大部分都认 为, 这个时期中西方列强之间通过政治外交努力和本国资本市场的力量竞相争夺 铁路特许权的竞争, 在某种程度上可以视为帝国主义时代的高峰。至少列宁等人 持有这种观点: 他认为, 中国被西方资本主义列强瓜分为各自势力范围, 是帝国 主义的典型案例 ${ }^{21}$ 。

虽然在名义上中国的铁路归 “中国铁路委员会” 管辖, 1895 年以后中国兴 建的所有铁路都是通过外债融资而建成的; 而这些外债又是由那些从清政府取得 铁路财产特许权和付款承诺的欧洲投资银行辛迪加承销的。在提供贷款的银行家 的控制之下, 中国铁路的建设、占有和运营都是由金融财团指定的经理人员来完 成的。当然, 这些贷款特征中最有争议的一点是它们包含了 “治外法权” 的内容。 治外法权事实上 “以债权国的法庭程序替代了债务国的商业行为” 22 。

中东铁路是治外法权的一个很好的例子。俄华银行于 1896 年提供了 500 万 两白银的贷款, 用于建设一条横穿满洲、将横贯西伯利亚的铁路和符拉迪沃斯托 克连接起来的铁路。俄国官员管辖着铁路本身及其相关路权等所有权利, 以及铁 路的所有收支。事实上, 这条铁路已经成为中国境内的一块俄国领土, 甚至发行 了自己的通货 ${ }^{23}$ 。日本也紧随其后, 在 1917 年对中国南满铁路的贷款中采用了 相同的方式。这条铁路是以铁路的产权为抵押的, 并成为日本在中国的第一块“领 地”。1897 年, 比利时为中国 Lung-Tsing-U-Hai 铁路提供贷款, 该贷款以铁路 本身以及铁路公司所有的财产和路权为抵押。

铁路的融资、占有、运营和管理, 都由外国人来控制, 是对中国的主权的明 显威胁; 这也成为当代学者广泛争论的一个问题。例如, 经济学家 A.P. Winston 在他 1916 年发表于《Quarterly Review of Economics》的文章中，就对外国公司

\footnotetext{
${ }^{21}$ Lenin, Vladimir Illyich, 1916, Imperialism, The Highest Stage of Capitalism.

22 Adams, Henry C. 1920, "International Supervision Over Foreign Investments," The American Economic Review, 10(1) 58-67.

${ }^{23}$ Dreyer, Edward L., 1995, China at War 1901-1949, p. 29.
} 
“垄断” 中国铁路的融资、建设和控制权提出了严厉的批评 ${ }^{24}$ 。与英国、法国、 俄国、比利时和日本形成明显对比的是, 美国根据各国对中国市场和资源利益均 沾和维护中国国家主权的原则, 主张对中国实行 “门户开放” 政策, 而不是由西 方列强瓜分中国, 实行殖民化 ${ }^{25}$ 。因此, 如果某项和约中对于铁路特许权的规定 偏向于某些国家, 美国通常都会予以反对。这项政策的一个例外, 或许也是中国 铁路特许权最重要和最引人注目的一个例子, 就是湖广借款。

在中国历史上, 湖广借款之所以重要, 有多方面的原因。借款的过程, 表现 了晚清时期地方政府和中央政权之间的争斗，也体现了中国的资本家们是如何力 争在本国筹集项目开发资金, 并且还揭示了外国特许权的政治后果: 一些历史学 家认为, 湖广借款引燃了 1911 年的辛亥革命, 结束了延续 3,000 多年的封建王 朝的统治。

“湖广”指的是中国中南部地区, 包括湖南省、湖北省以及四川省的一部分。 1905 年, 在湖广总督张之洞的批准和参与下, 湖广地区的地方绅士、官员和商 人组成财团, 获得了准许建设一条贯穿湖广地区的铁路的特许权。在此之前, 地 方政府还曾成功地游说中央, 通过支付一定赔偿而取消了 J.P. Morgan 美中开发 公司的开发权, 这事实上还阻止了一家比利时铁路开发公司试图建设从广东到汉 口铁路的计划。该铁路是贯穿湖广地区、联结通商口岸和中国内地铁路交汇点的 关键线路, 取消外国公司的特许权, 就为本国企业从事开发打开了方便之门。

取消美国企业的特许权之后, 湖广的地方官绅们为取得特许权而积极奔走。 举例而言, 广东到汉口铁路的建设是由两家获得特许权的本国企业共同承担的: 一家在广东, 另一家在湖南。广东那家企业所经历的问题, 在某些方面反映出了 中国法制框架形成时期企业治理的某些问题。这家企业是在筹资方面最成功的中 国企业之一。它筹集到了全部的 4400 万两白银, 其中有相当部分来自于海外的 中国投资者。考虑到我们前面讨论过的资产分散化的问题，中国海外投资者的参

\footnotetext{
${ }^{24}$ Winston, A.P., 1916, “Chinese Finance Under the Republic,” Quarterly Journal of Economics 30(4) August, p. 738-779.

${ }^{25}$ Scholes, alter V. and Marie V. Scholes, 1970, The Foreign Policies of the Taft Administration contains a detailed description of the U.S. China policy.
} 
与就是一个非常有意思的问题了。初始的认购价格为每股一两白银, 这吸引了众 多的本国投资者。在《North China Herald》杂志中有一段记录, 尤为生动地描述 了投资者踊跃购买铁路股票的情景 :

购买股票的不仅仅是有钱人, 就连那些穷的不能再穷的人, 甚至是那些根本 不会有闲钱、几乎没有足够的钱来维持生计的人，也都来购买几股 ${ }^{26}$ 。

这些股票中有相当部分是通过地方慈善机构出售给公众的; 这些机构无法自 行认购股份, 但仍为自己保留了选举权。同样是在这些机构的帮助下, 广东商会 的主席不顾股民的强烈抗议而取得了公司的控制权, 并推动了代理人之间进一步 竞争; 最终, 地方当局直接介入公司的管理。该公司 1909 年的内部审计帐目暴 露了严重的挪用现象。管理者通过夸大支出在账簿上弄虚作假, 并在许多令人怀 疑的交易中高价购买企业设备。

19 世纪末 20 世纪初转向国内融资的运动, 通常被认为是社会基层对于外部 融资及外国企业控制中国基础设施的一种民族性质的反应, 但这种归纳或许过于 简单化了。如果我们考虑到 Rajan 和 Zingales 关于地区竞争的假设, 则 20 世纪 初期中国的地方绅士在开发企业中的作用尤为重要。这个时期中国的地方绅士是 一个受良好教育的社会精英阶层, 从政治角色来说, 他们是中央政府和民众之间 在地方上的中介, 并对当地的商业活动有相当的控制力和影响力。早在中国铁路 发展史的早期, Er-Tu Zen Sun 就认为:

中国铁路所处的环境往往给它们的正常运作造成阻碍。这些阻碍来自不 同的方面。有些时候, 这种阻碍来自于铁路发展初期各地的地方绅士：1906 年, 在 P'ing hsiang-Hsiangt'an 铁路, 有 3000 两以上白银落入铁路沿线有势 力的人物 ; 例如 “保护铁路” 的工资就是为了获得在这些人物势力区域内铺 设铁轨的权利。

\footnotetext{
${ }^{26}$ Quoted in Lee, En-han, 1977, “China's Quest for Railway Autonomy: 1904- 1911: A study of the Chinese Railway Rights Recovery Movement,” Singapore University Press. P. 104.
} 
Rosenbaum 在对 1910 年长沙粮食暴动的研究中发现, 在利用民众对外国人 铺设铁路的排外情绪进而反对清政府的事情上, 地方绅士起到了关键的作用。事 实上, 张之洞就曾经驳回了地方商人行会的一项建议, 该建议要求为一个主要由 地方绅士控制的半官方的企业提供资金, 以便在湖南建设一条铁路。根据 Rosenbaum 的说法, 这个企业的问题类似于上文中的广东企业。

1907 年到 1908 年之间这条铁路的运营纯粹是一场灾难。许多商人成为股东, 但是几乎没有得到任何权力。1907 年底, 大量私人股撤出。那些被排斥在管理 工作之外的人仍继续抗议, 但是我们并不清楚他们针对的目标是那些从事管理的 无能的地方绅士, 还是拒绝他们将公司改组为纯粹私人企业的政府 ${ }^{27}$ 。

总而言之, 那些代替了美中开发公司而取得铁路开发特许的本国铁路公司, 是非常不幸的。中国本土的铁路开发公司的形成, 确实有潜力成为推动个人投资 于本国企业的催化剂。海外华人对这些企业的积极参与, 说明国内企业甚至有可 能吸引某种国际资本。然而不幸的是, 尽管这种自力更生的铁路开发计划值得称 赞, 尽管大大小小的中国人都愿意将自己的积蓄投资于这些企业, 但企业治理的 基础结构在中国仍没有形成。可悲的是, 这种落后的企业治理结构, 加上在特权 和势力的影响下运作的根深蒂固的绅士阶层, 使这些企业很难同国外同行竞争, 因为外国企业在治理体系下与国外部分整合在一起; 而这种治理体系, 又是那些 已经很好地对资产实行分散化的海外投资者们所熟知的。

最终, 尽管存在民族情绪和地方利益集团, 张之洞仍只允许英国对铁路提供 融资。这一举动甚至可能影响到长江地区外国力量之间的微妙均衡 ${ }^{28}$ 。为抵消英 国的优势, 德国、法国以及最终美国都要求参与到铁路的贷款、建设、以及控制 之中。最终的结果, 是四个国家平分了价值六百万英镑的贷款, 同时四方还就铁 路不同部分的开发权进行了详细的谈判。之后, 作为此次交易的最后一步, 张之 洞说服清政府对所有铁路开发都采用国有化，因为本国开发者资本化程度的低下 使得铁路开发不能顺利开展; 这一举动显然激怒了绅士阶层。至此, (清政府)对

\footnotetext{
${ }^{27}$ Rosenbaum, Arthur L., 1975, "Gentry Power and the Changsha Rice Riot of 1910,” Journal of Asian Studies
} 34(3) May, p. 689-715. 
这条铁路本国股东权利的剥夺就完成了。

1911 年, 这一笔冠冕堂皇的贷款, 即年利 $5 \%$ 、期限 50 年的湖广铁路偿债 基金黄金贷款, 最终以清政府邮政通讯大臣的名义签订。债券上也注明了借款担 保的细节。除铁路的净利润之外, 这笔借款的抵押还包括：(1)每年 200 万两白 银的湖北省普通厘金; (2)湖北省每年为河防而征收的盐附加税 40 万两白银; (3)1908 年 ( 借款谈判期间 ) 新定的盐附加税, 每年 300 万两白银； (4)湖北省征 收的湖广地区内部各省间大米进口税, 每年 250 万两白银; (5)湖南省每年 200 万两白银的普通厘金, 以及(6)湖南盐政使每年分得的正常盐政厘金 25 万两白银。 可以想见, 在铁路建设期间, 这些抵押对于偿付债券持有人是至关重要的。虽然 湖广地区的百姓确实得到了一条现代化的铁路, 但他们也为它付出了相当的代 价, 包括盐税、新的盐税、粮食税以及省间流通税, 并且这些税收还将随着铁路 的延伸而不断加重。此外, 地方上的企业事实上已经被剥夺了铁路的开发权; 地 方官员在清政府的授意下，把这些权利转交给了外国人。

Kuhlmann 发现了关于湖广铁路借款的影响的一个非常有意思的记述。Chang Kia Ngau 在 China's Struggle for Railroad Development 中谈到 :

国有化的新政策一经公布，立即招来了强烈的反对。民众的愤怒再次上 升到非同寻常的地步。最严重是四川, 那里发生了罢市和罢课。由于地方立 法机构的主席和副主席相继被捕, 机构陷入一片混乱。省府成都的百姓全部 到总督官邸示威, 卫兵向人群开枪射击, 数十人丧生。这更激怒了百姓, 他 们拒绝再支付任何税收。到 7 月中旬, 数千人围攻成都, 并得到了附近城镇 和乡村的支持。与此同时, 武昌一一湖北的一座与汉口隔长江相望的城市 一一爆发了革命, 这也大大鼓舞了四川人民。为镇压这一运动, 清政府派出 端方将军率领一支装备精良的部队前往四川, 但是这位将领在途中即被暗 杀; 四川总督也遭到了同样的命运。1911 年 9 月 10 日, 四川人民宣布脱离 旧政权而独立, 并对革命事业表示同情。10月16 日, 载淳代表小皇帝宣布

\footnotetext{
${ }^{28}$ Scholes and Scholes p. 127.
} 
退位 ${ }^{29}$ 。

上文记述了革命前夕的一系列暴动和起义，而这个时期中发生的关于铁路路 权最重要的一次暴动- - 1910 年长沙粮食暴动- - 则很明显地说明, 在反对清 政府的过程中，地方绅士起到了鼓动作用 ${ }^{30}$ 。由于清政府在铁路开发融资过程中 偏祖外国投资者, 保路运动针对的目标既有满洲统治者, 也有外国的商业企业。

湖广铁路借款是清政府所借的最后一笔外债, 20 世纪 20 年代, 这笔借款被 废除。直到 30 年代末期, 中国政府仍继续为开发铁路而举债- - 1934 年、1935 年、1936 年及 1937 年都有铁路借款。我们掌握的资料中唯一一段明显没有铁路 债券发行的时期是 1926 年和 1927 年 时间上刚好是蒋介石致力于统一中国的北 伐战争时期 ），还有 30 年代前四年的世界经济危机时期。除了这些时间之外， 即使有内战和外国侵略，外国投资者仍继续投资、开发中国铁路。

\section{$V$ ．证券组合分散化和公司治理结构}

下面, 我们将着重对中国资本市场发展具有重大影响的两个因素: 证券组合 分散化和公司治理结构。

\section{1 证券组合分散化}

和中国有限的国内资本市场相比，欧洲资本市场的一大特点在于：即使是小 规模投资者也可以持有高度分散化的投资组合。根据金融理论，投资组合分散程 度的不同可能会给中国股票和证券的边际投资者带来好处。仅仅因为外国投资者 持有高度分散化的证券组合这一事实, 可能就可以导致外国投资者比中国投资者 拥有更低的融资成本，从而在对中国投资项目的竞争中支付较高的价格。

那么, 在一个非均衡的世界中一一市场的分割使得一个集合中的投资者们可 以通过国际投资分散他们的资产组合，而另一个集合中的投资者只能持有一个国 家的资产一一情况又将是如何呢？让我们来考虑一下下面这个普通的例子。有两

${ }^{29}$ Quoted in Kuhlmann, Willhelm, China's Foreign Debt, self-published, 1983, p.73.

${ }^{30}$ Rosembaum, Arthur, 1975, "Gentry Power and the Changsha Rice Riot of 1910," Journal of Asian Studies, 
个彼此分隔的市场: 市场 1 和市场 2 , 其中持有第一个市场股票的投资者们不能 持有第二个市场的股票, 反之亦然。我们假定第一个市场为中国, 第二个市场是 19 世纪末 20 世纪初的欧洲资本市场。现在考虑一个新的项目 $\mathrm{n}$, 这个项目产生 随机的现金流量, 因而需要融资。项目的所有人必须考虑哪个市场能够给予最优 惠的条件。事实上, 他将选择资本成本即预期回报率 $\mathrm{E}\left[\mathrm{Rn}_{1}\right]$ 或者 $\mathrm{E}\left[\mathrm{Rn}_{2}\right]$ 较低的那 个市场。我们假定均衡资产定价模型 CAPM 在两个市场上都分别成立, 两个市 场上代表性投资者的风险回避系数相等, 每个项目的规模在各自市场上都是微不 足道的, 并且两个市场上的无风险回报率 $\mathrm{R}_{\mathrm{f}}$ 一样。如果我们用通用的符号来表 示 $\beta$ 、相关系数、方差和协方差, 并假定风险回避系数为 2 , 那么决定两个市场 相对资本成本的条件就显而易见了:

$$
\begin{aligned}
& E\left[R_{n 1}-R_{f}\right]=E\left[R_{n 2}-R_{f}\right] \\
& \beta_{n 1}\left[R_{m 1}-R_{f}\right]=\beta_{m 2}\left[R_{n 2}-R_{f}\right] \\
& \frac{\sigma_{n 1}}{\sigma_{1}^{2}}\left[R_{m 1}-R_{f}\right]=\frac{\sigma_{n 2}}{\sigma_{2}^{2}}\left[R_{n 2}-R_{f}\right] \\
& \frac{\sigma_{n 1}}{\sigma_{1}^{2}} \theta \sigma_{1}^{2}=\frac{\sigma_{n 2}}{\sigma_{2}^{2}} \theta \sigma_{2}^{2} \\
& \sigma_{n 1}=\sigma_{n 2}
\end{aligned}
$$

为保证所有者对于两种融资渠道的偏好无差异, 项目 $\mathrm{n}$ 关于分割市场组合的 现金流的协方差必须相等。但是, 如果协方差不相等呢? 公式 1 表明, 当项目关 于市场指数 1 的协方差较大的时候, 市场 1 所要求的回报率就要比市场 2 大。对 于中国, 我们可以很自然地假定, 相对于世界其他国家企业以市场为权重的资产 组合相比, 中国的开发项目对于国内企业以市场为权重的资产组合具有较高的协 方差系数。这表明, 如果市场完全分割的话, 那么国内市场上的资本成本要相对 高一些。

但是, 如果我们考虑到类似于 CAPM 这样的定价模型成立的前提条件-一 
特别是流动性的要求一一在上一个世纪的中国可能并不现实, 那么上面的解释则 是值得商榷的。此外我们并不清楚中国的某个铁路项目与中国国内其他经济活动 所具有的相关系数, 同它与某个倾向于各个铁路公司的世界性指数的相关系数相 比, 哪一个更高。这是一个有待研究的实证性问题。最后, 在上个世纪之交, 上 海已经有了银行和股市; 这是否使得中国的投资者能够在国际间分散他们的投资 组合一一从而事实上使得我们上述的市场分割假设不成立? 同样, 这也是一个需 要进一步研究的问题。

等式 1 的特点在于用协方差表示条件, 但这些结果可以分解为相关系数和标 准差, 从而可以帮助我们考虑分散化活动的相对重要性。在什么条件下, 会出现 市场 2 上的资金成本低于市场 1 的情况？假定相关系数为正：

$$
\begin{aligned}
& \sigma_{n 1}>\sigma_{n 2} \\
& p_{n 1} \sigma_{n} \sigma_{1}>p_{n 2} \sigma_{n} \sigma_{2} \\
& \frac{p_{n 1}}{p_{n 2}}>\frac{\sigma_{2}}{\sigma_{1}}
\end{aligned}
$$

公式 2 表明, 即使在 $\rho_{n 1}=\rho_{n 2}$ 的情况下, 如果全世界 (不包括中国) 财富组 合的标准差比中国市场指数的标准差小, 所有者将发现外部融资更有吸引力。正 如 Stulz (1999)和当代国际投资分析者所指出的, 通过地理上的投资分散化, 可 以降低一个全球投资者的资产组合风险。如果在一个世界上，一组投资者采取了 分散化的策略而另外一组没有, 那么, 对于同一资产, 采取分散化策略的那组投 资者当然会愿意比后者支付更多。当所增加的资产与国内投资者投资组合相关程 度更高, 以及国内资产组合的变动更大的时候, 这个结论就可以成立。如果 100 年前中国的情况确实如此的话, 我们可以预料, 如果给国内外投资者的条件一样, 那么国内的投资者将不愿意投资于国内项目。当然，这种分析对于中国资本市场 的相对发展程度可能作了过多的假设。 
19 世纪西方与中国的冲突, 是技术与文化的冲突, 同时也是金融体系的撞 击。19 世纪欧洲政府、企业的债券和股票市场的发展突飞猛进, 远非当时的中 国所能比拟。与此形成鲜明对比，日本则于 19 世纪致力于发展国内资本市场。 和中国一样, 日本在 19 世纪 70 年代也发行了大量的外国债券, 但是和中国不同 的是, 自 19 世纪 90 年代中期, 日本几乎全部的融资都来自于国内的政府债券市 场, 并且, 日本国内经济之所以长足发展, 很大程度上得益于从明治时期以来日 本成功仿效欧洲而营造的商业环境 ${ }^{31}$ 。相比之下, 从 19 世纪中叶到末期, 中国 的金融体系中却充斥着从事小规模贷款的当铺和小钱庄, 从事资金远程汇兑的汇 兑银行, 以及 19 世纪 60 年代之后在主要港口出现的从事外贸关税收付业务的关 税银行 ${ }^{32}$ 。由于尚未形成资本市场，大部分的资金借贷和股权交易活动都是私人 进行的。政府借款不采取公债的形式, 并且由于某些原因, 认为对借款支付利息 是无法接受的。对政府的无息贷款, 被认为是一种义务。在《晚清金融史》中, 关于国内债券发行问题, Stanley 引用了 19 世纪 70 年代一位政府官员很有说服 力的说法： “借款是官员向老百姓借款, 要(官员)支付利息就很不合适了。33” 政府拒绝对资金的时间价值作出补偿的行为也是有利亦有弊的。政府在汇兑银行 存入税收收入, 但不要求取得相应的利息, 也就是利用这些存款可能获得的收入; 这在当时被看成一种恩惠。可以理解，政府官员对于政府放贷的态度也使它很难 从自己的臣民手中借钱。这样, 由于缺少一个流动性的资本市场, 资产分散化的 效果相对就小了。

有一些历史数据可以表明, 这个时期外国融资建设的资本项目所要求的回报 率, 要低于外部融资的基础设施项目。Pommeranz 引用资料说明, 18 世纪末期 天津的银行和当铺向政府和主要商人索取的 “基准利率” 是 10\%到 $12 \%$ 。对中 国 20 世纪初期利率情况的更广范的考察表明,农业贷款年利的中等水平为 $30 \%$ ， 而对工商企业的贷款则要求 $7 \%$ 到 $8 \%$ 的利率, 同时分享股本 ${ }^{34}$ 。Lee 指出, 在传 统的投资方式即房地产和当铺之外, 能够产生高回报的还有其他投资渠道一一中

\footnotetext{
31 Suzuki, Toshi, 1994, Japanese Government Loan Issues on the London Capital Market 1870-1913, Athlone Press, London.

${ }^{32}$ See Stanley, John C. Late Ch'ing Finance: Hu Kuang-Yung as an Innovator, Cambridge, Massachusetts, 1970. Pages 19-29.

33 Ibid. p. 65.

${ }^{34}$ Huenemann, p. 128-129.
} 
国的资本家们都积极投资于出口导向的产业, 如纺织业、食品加工业等。相比之 下, 向政府贷款或者购买铁路债券或股票, 就显得不那么有吸引力了 ${ }^{35}$ 。遗憾的 是, 由于不存在大规模的公开资本市场, 迄今为止对于中国当时的投资回报率仍 没有系统性的研究。我们只知道, 当时很难吸引国内投资。从 19 世纪末到 20 世纪初, 中国人并不是政府借款和国内开发项目的主要投资者; 对这个现象的一 个简单的经济学解释是, 考虑风险因素, 当时有更为优越的其他投资方式。

来自欧洲的大规模资本流入, 以及国际资产组合分散化的积极实施，必定对 欧洲资本流入的市场产生显著的影响。Stulz (1999)认为, 当代的全球化趋势通过 资本分散化效应降低了资本成本。同样出于对该问题的兴趣, Beckaert 和 Harvey (1995，1998)深入考察了在新兴市场逐步向世界资本市场整合的过程中, 资本成 本和市场风险的变动情况。他们和其他研究世界资本市场自由化的研究者所得到 的一般结论是, 随着外部投资者逐步获准介入国内投资项目, 资本成本也将降低。 资本成本的降低很明显有积极作用一一原先由于回报率低而不具有吸引力的资 本项目, 现在也能够得到资金融通了。利率的降低可以对经济的发展起到不同寻 常的刺激作用。Hou(1965)和 Huenemann(1984)都证实了 19 世纪末期外国投资引 起的中国经济的急剧扩张。但是, 这个问题的另一面是, 在对本国资产控制权的 竞争中，未能实现资产分散化的国内投资者就处于相对不利的地位。

国内和国际投资者的这种竞争，正是 Rajan 和 Zingales(2001)研究的主题。 他们指出, 即使国际融资很明显更有效, 国内的投资者还是可能会非常反对竞争。 可以想见, 这种反对的动因在于由本国掌握管理的控制可以带来额外收益。如果 这些权利在受到威胁时没有得到相应的补偿, 并且地方集团未能得到严格的法制 制约, 其潜在的后果将是非常严重的。

\section{2 投资者保护的不均衡和公司治理结构}

LaPorta(1997，1999，2000)等人在一系列非常有影响的世界资本市场跨地区

\footnotetext{
${ }^{35}$ Lee, op.cit. P. 133.
} 
研究中表明, 保护投资者的利益和得到他们的投资同等重要。事实上, 如果没有 对这些权利的保护, 资本将非常稀缺。他们证明, 一个国家里企业资本能否成功, 最重要的因素之一就是当地的法制环境。他们以及后来的研究者的实证研究表 明, 一个国家的法制传统决定了对投资者权益的保护程度, 对投资者权益的保护 反过来又决定资本市场的规模和运作, 而资本市场的规模和运作又影响着资本在 企业之间配置的效率 ${ }^{36}$ 。是什么决定了一个国家的法制体系呢? 殖民主义是一个 主要原因。殖民主义虽有种种过失, 但仍可以被认为是不同国家之间法制框架的 输出机制。LaPorta 等人表明, 即使政府本身不再是殖民地政府, 法制框架仍可 能继续为本国的私营企业提供特殊待遇。进一步考虑, 我们可以把殖民世界看作 一种形式的政治一经济均衡体系, 在这个体系中, 对投资者有利的世界法制体系 将有助于资本配置效率的提高以及私有企业的形成。当然, 这个问题也有另外一 个方面, 就是当国家主权问题的重要性超过经济动因的时候。

晚清时期, 中国的商业部门经历了非同寻常的变化。虽然中国当时仍然是一 个传统的农业经济, 但外贸活动的开展一一其中一部分是由于 19 世纪英国的炮 舰政策的推动一一为国内的制造业也提供了相当的机会。有人指出, 中国在明代 末期就出现了资本主义的萌芽, 特别是在采矿业和制造业; 但几乎可以肯定的是, 与西方国家的接触、特别是在主要通商口岸的活动, 才是本国企业发展的主要动 力 $^{37}$ 。欧洲国家商业活动和金融机构在诸如上海和香港等通商口岸的成功, 在国 内引起了一阵推进中国金融技术的运动。

虽然从 1845 年开始外国银行就开始在中国开展活动, 但中国有竞争力的现 代金融机构, 直到 1891 才随着年中国国民银行的成立而出现。这家银行的资金 来源于国内外的投资者 ${ }^{38}$ 。Sin Cun Bank of China (中国首家储蓄银行)于 1906 年 成立 ${ }^{39}$ 。中国第一家合资企业成立于 19 世纪 70 年代, 上海证券交易所的活动也

\footnotetext{
36 Jeffrey Wurgler, 2000, "Financial Markets and the Allocation of Capital," Journal of Financial Economics, 58(1) 187-214, October.

37 See, for example, Xu, Dixin and Wu Chengming, 2000, Chinese Capitalism, 1522-1840, St. Martins Press, New York.

38 Lam, Otto, 2001, "Banks and Banknotes of Hong Kong:1846-1911" The Journal of Hong Kong Numismatics Society, Hong Kong.

39 See Pan, Junxiang and Ma, Chuande, 1998, Currencies in Old Shanghai, Shanghai People's Fine Arts Publishing House, Shanghai. P.35
} 
可以追溯到 19 世纪 80 年代, 但是我们找不到足够的历史材料证明这些早期的中 国资本市场在经济上具有什么重要性 ${ }^{40}$ 。20 世纪开始不久, 中国政府采取措施发 展法制架构, 目的是促进中国企业部门的发展, 以便与外国企业投资相竞争 ${ }^{41}$ 。

1904 年, 为了便利国内企业的发展, 同时限制外国股东和债权人对控制权 的掌握, 中国政府的商务部门针对商业法令推行了一系列的改革, 并于 1905 年 进一步制定了破产法。根据一项估计, 从 1903 年到 1908 年, 上述努力为中国 265 家新企业吸引到了约一亿三千万两白银(约合一亿美元)的资金 ${ }^{42}$ 。这些新企业 之中的 10 家是铁路公司, 在中国 1904 年公司法案之后注册的企业总资本中, 这 些公司的资本额就占了将近一半。除根据正式法令成立的公司之外, 为了向铁路 建设提供资金并直接与国外特许权人竞争，当时还出现了相当多其他形式的组 织。表一(取自 Lee, 1977)列出了 1903 年到 1909 年间成立的 19 家铁路公司, 其 中有许多得到了地方政府的正式补贴; 这些补贴来自于政府对大米、鸦片、鸦片 烟斗、海盐、彩票、木材、邮票、房租、官员薪水和土地所征税收。如表所示, 这些投资能保证的回报率并不高一一大约在 $4 \%$ 到 $7 \%$ 之间; 当然, 我们并不清 楚这其中是否包括资本增值的可能, 因为不论是股权还是债权, 这种证券形式都 还没有得到认可。我们所确知的是, 筹资的目的并没有达到。虽然政府对这其中 的许多企业提供了补贴, 实际上筹集到的资金尚不足实际所需数额的一半。这是 不是因私人资本的短缺呢? 似乎不太可能。20世纪 30 年代对中国国内财富的预 计, 和中国许多公民的主要个人财富的统计, 都表明中国有相当的能力在国内为 自己的国防力量和基础设施建设筹资。显然, 问题在于中国缺少对于股票发行和 债券承销过程的经验, 而欧洲市场对此则早已掌握 ${ }^{43}$ 。

另一个问题在于公司治理。虽然中国政府进行了法制改革, 也采取措施规范 本国企业, 但事实表明, 1904 年改革之后成立的许多新企业, 缺乏必需的治理 结构和管理技能, 也缺乏应有的相对于政府控制的独立性, 从而使他们无法同外 国企业有效竞争。Lee 通过对这个时期中国特许经营的铁路企业的研究, 将它们

\footnotetext{
${ }^{40}$ Kirby, William C., 1995, "China Unincorporated: Company Law and Business Enterprise in Twentieth Century China," Journal of Asian Studies 54(1) February, 43-63.

${ }^{41}$ Ibid.

42 Lee, En-Han, 1977, China's Quest for Railway Autonomy: 1904-1911, Singapore University Press, Singapore, 1977. P. 268.

${ }^{43}$ For macroeconomic estimates of savings capacity, see Riskin, Carl (1975). For a discussion of personal fortunes see Huenemann (1982) p. 126.
} 
失败的原因归结为以下几个方面：(1)由于存在其他资本用途而导致的资本化程 度低下; (2)工程、技术和技能缺乏; (3)管理技能缺乏; (4)官员腐败, 营私舞弊44。 当然, 第一个原因即资本化程度低下, 是问题的表现, 而不是原因。中国人之所 以不愿意投资, 既可能是由于这将与那些能够在国际间分散资本组合的外国投资 者产生竞争, 也可能是由于投资者对于企业治理问题的理性预期, 也可能是二者 兼而有之。在下文我们对铁路融资的讨论中, 我们将具体分析一家具有特殊重要 性的企业。

总而言之, 外国对中国政府税收收入的控制, 以及给予外国铁路特许权人的 “治外法权”，非常接近于一种为投资者提供保护的合法化的 “帝国主义”过程。 虽然可以想见，这对于中国铁路的所有投资者以及中国债券的所有持有人都意味 着利益的增加，但由于大部分铁路和债券的投资者是外国人，因此投资者保护措 施带来的好处不成比例地倾向了外国人。中国 1904 年和 1905 年商业法令的改革, 为企业投资提供了一个国内基础。但由于这些法令仍不成熟, 加之存在治理上的 重大问题, 它们并未真正地起到保护少数股东权益的作用。

\section{VI. 结论与政策}

在某些时候, 金融对于国家政权的政治发展有关键性的作用, 这种作用就体 现在对于政权的形成和覆灭的作用上。中国第一次和世界金融市场的接触, 就和 全球政治形势密不可分。一个世纪以前的世界金融市场至少对中国而言绝非是自 由放任; 。某些借款谈判, 其出发点是为保护投资者, 但最终都成为殖民化中国 的手段。铁路对于外国势力在中国的延伸, 甚至是外国法律环境对中国的渗透, 都起到了关键作用。

但是, 如果没有金融的根本驱动, 以上这些都绝无可能发生。在这篇文章中, 我们确定了两个关键性的金融动因, 在某种程度上它们并无国界之分。首先我们 认为, 英国和欧洲大陆的投资者们都富有经验; 他们对资产国际分散化的需求,

\footnotetext{
${ }^{44}$ Lee, Ibid. p. 132-141.
} 
加上这些国家经济发展的高水平, 都使得外国的投资者们处于相对有利的地位。 中国的政府债券在伦敦市场上很顺利地得到了发行, 并且, 由于西方国家同中国 政府就投资者利益的保护进行了谈判, 中国债券的收益率一直维持在比较稳定的 水平。投资者们还投资于那些具有潜在高收益性的基础设施项目, 尤其是铁路。 我们认为, 由于外国投资者具有良好流动性的资本市场, 而且在全球实现了资产 组合的分散化, 他们在对中国的项目进行投标时, 就处于相对有利的地位。欧洲 和日本都形成了活跃的资本市场, 能够有效地动员小规模投资者的储蓄。当代资 产组合理论认为, 外国投资者们由于能够在全球投资实现资产分散化, 因而同中 国本国的投资者相比能够接受更低的回报率。

我们集中考察的第二个因素是对投资者的保护和公司治理。尽管对中国人来 说, 赋予外国投资者的 “治外法权” 让人难以接受, 但是历史事实表明, 这种权 力对于保护相关企业的开发和运作免受地方利益集团的干扰是必需的。20世纪 初, 由地方绅士主导的从外国人手中收回铁路开发权的运动, 曾被认为是一种收 回中国人权力的国民性质的运动。这些企业中股东的经历表明, 中国本应能够形 成一个真正的资本市场, 但是由于对作为少数股东的本国投资者保护不力, 这种 潜力就无法变成现实。

一个世纪之前金融对中国政治的影响并非只是历史研究者关心的问题。面对 全世界对新兴市场投资的再次升温, 中国做好准备, 希望能够吸引足够的金融资 本。不论从政治上还是军事上, 中国现在都已经远比 100 年前强大, 因此, “治 外法权” 的问题现在并不像以前那样危险了。但同时, 值得注意的是, 部分地由 于中国金融史的原因, 中国对于侵犯领土主权的问题仍非常敏感。这也是可以理 解的。

在我们的文章中, 对于中国与全球金融体系的第一次遭遇, 我们集中研究了 两个关键因素。第一个因素是资本市场发展和资产组合分散化的问题, 特别是国 内外资本分散化程度不均等所带来的后果。今天, 当中国出现商业机会的时候, 国内的投资者们能否在为项目融资时同外国投资者竞争呢? 如果要保证这种可 
能性, 一种方法是应当让国内的投资者有可能向国外投资; 一是可以采用直接方 式, 即实现外汇交易自由化, 二是采用内部方式, 即允许外国股份在中国的证券 交易所上市交易，并建立中国投资者所能够参与的国际共同基金。虽然这样做的 结果是一些中国的资本可能外流, 但它能够保证国内外投资者的机会集合均等, 从而中国的投资者和外国的投资者将要求同样的回报率, 并且中国企业的边界投 资者也不再一定是外国人。

1904 年企业法公布之后旋即兴起一股投资热潮, 但却由于企业治理问题上 的失败而备受挫折。对于中国来说, 这些问题也并不值得大惊小怪。即使是现在, 对于许多国家来说，企业治理也是一个极其棘手的问题。对于外国融资所附加的 不平等权利和特许权, 有一种解释认为, 这是控制新兴国家市场投资风险的一种 方式。但 100 年前中国的经验表明, 投资者和外国人同样需要保护以防止出现没 收财产的情形。随着中国的金融管制当局对投资的法制框架实现现代化，今天中 国的资本市场取得了迅速的发展。有望防止出现国内外投资者待遇不均等的一种 措施是：对国内股份，集中精力保护好个人投资者的权益，同时在国内资本市场 的环境中，通过诸如企业竞争控股、财务的公开和披露以及内部人交易法律等问 题, 对中国的制度设施加以考验。一旦证券管理者们完成了对这些问题的试验, 那么，消除国内外股份之间差异的时机也就基本成熟了。

对那些有意于支持中国资本市场发展的国际投资团体来说, 从这其中也能够 得到很多教益。虽然随着类似于世界银行等国际贷款机构的发展，国际金融体系 在发展初期所受到的政治上的滥用已经得到了纠正, 但在当前这一多变的时代, 在国内和国际的融资活动中仍可能存在不对称的竞争。虽然我们很容易以为为中 国经济发展筹集资金的方式中最有效率、成本最低的就是在外国而不是本国市场 上融资, 但国际社会必须认识到, 将国内股东排斥于融资所获利润之外有可能引 起相当严重的问题。当前, 中国证券市场上存在的 “双上市” 结构, 很有效地鼓 动了一一或者在某种程度上说是培育了一一国内投资者对本国资本市场的关注。 国际社会应当尽全力支持为保证中国人投资再度兴起所作的努力, 即容许对市场 规制和股权分散化采用一个渐进的试验过程，同时逐步减少国内外股份之间的差 
异。

不论是左派人物还是右派人物都对当前的全球金融体系提出批评, 这似乎已 经成为一种时髦: 批判的理由, 要么是说它扭曲了投机的因素, 因为政府可能提 供紧急财政援助; 要么是说它对一些在环保、政治发面不令人满意的项目提供了 融资。这些批评家应该考虑问题的另一个角度。100 年之前, 中国与全球化的第 一次接触所形成的政治环境最终使中国却抛弃了国际金融体系。现在, 随着世界 市场整合的程度逐步恢复到上个世纪末的水平, 国际资本市场上发展情况的不平 衡所引起的问题也类似于上世纪末的问题。有人认为, 新的均衡可以迅速、轻易 地实现，而不会产生什么社会或政治后果; 国际金融体系的设计者们应当对这种 观点持谨慎态度。

我们对中国金融史研究得到的不仅仅是这些直接的、实际的结论, 还有其他 的收获。中国资本市场最终消失的原因在于内部, 而不是外部。简而言之, 在中 国最终取得胜利的是列宁的帝国主义论断。虽然现有的实证研究表明对外国投资 者利益的保护-一尤其是在持股人有很大影响力时一一可能最终是有利于经济 发展的, 但是实际的资料与此却有很大距离。由于爆发了革命, 中国和俄国都撤 出了世界资本市场从而延缓了各自资本市场的发展。更长期的历史验证表明, (对 产权保护和资本市场发展)理论和(中俄两国的)现实之间的差距是内生的。对国外 投资者权利的成功保护和对国内投资者权利保护的不力, 对于国内外金融索取权 被废止和消除负有同样重要的责任; 也就是说, 外部投资者各种财产权利的扩大 和确定对于企业的成功固然非常重要, 但有的时候这种做法也将当地股东排斥于 生产部门之外。 
Reference

Adams, Henry C., 1920, "International Supervision Over Foreign Investments," American Economic Review, 10(1) March, 58-67.

Asiaticus, 1937, "The New Era in Chinese Railway Construction," Pacific Affairs, 10(3) September, 276-288.

Atkin, John Michael, 1977, British Overseas Investment: 1918-1931, Arno Press, New York.

Bakaert, Geert. "Time-Varying World Market Integration," Journal of Finance, 1995 403-444.

Bakaert, Geert and Lundblad, 2000, Chris "Does Financial Liberalization Spur Growth," NBER working paper

Edelstein, Michael, 1982, Overseas Investment in the Age of High Imperialism, Methuen and Co. New York.

Feis, Herbert, 1930, Europe, The World's Banker: 1870-1914, Yale Press, New Haven.

Ferguson, Niall, 2001, The Cash Nexus: Money and Power in the Modern World, 1700- 2000, Basic Books, New York.

Hou, Chi-ming, 候志明 1965, Foreign Investment and Economic development in China 1840-1937, Harvard Press, Cambridge.

Huenemann, Ralph William, 1984, The Dragon and the Iron Horse: the Economics of Railroads in China 1867-1937, The Council on East Asian Studies, Harvard University, Cambridge.

Kirby, William C., 1995, "China Unincorporated: Company Law and Business Enterprise in Twentieth Century China," Journal of Asian Studies 54(1) February, 43-63.

Kuhlmann, Willhelm, "China’s Foreign Debt”, self-published, 1983, p.73.

LaPorta, Rafael, Florencio López-de-Silanes, Andrei Shleifer and Robert Vishny, 1997, "Legal Determinants of External Finance," Journal of Finance, 52(3), 1131-1150.

LaPorta, Rafael, Florencio López-de-Silanes, Andrei Shleifer and Robert Vishny, 1999, “Corporate Ownership Around the World," Journal of Finance, 54(2), 471-517. 
LaPorta, Rafael, Florencio López-de-Silanes, Andrei Shleifer and Robert Vishny, 2000, "Investor Protection and Corporate Governance," Journal of Financial Economics, 58(1), p. 1-25.

Lee, En-Han, 李恩涵 1968, “China’s Response to Foreign Investment in her Mining Industry (1902-1911)," Journal of Asian Studies, 28(1) November, 55-76.

Lenin, Vladimir Illyich, 1916, Imperialism, The Highest Stage of Capitalism.

Lewis, Cleona, 1948, The United States and Foreign Investment Problems, The Brookings Institution, Washington D.C.

Lowenfeld, Henry, 1909, Investment an Exact Science, The Financial Review of Reviews, London.

Mauro, Paolo, Nathan Sussman and Yishay Yafeh, 2000, "Emerging Market spreads: Then Vs. Now," Working Paper International Monetary Fund and Hebrew University.

Mosley, Layna, 2000, "History Repeating Itself? Sovereign Borrowing Before the First World War," Working Paper, Department of Government, University of Notre Dame.

Obstfeld, Maurice and Alan M. Taylor, 2001, "Globalization and Capital Markets" NBER Working Paper.

Pan, Junxiang 潘君祥 and Ma, Chuande 马传德, 1998, Currencies in Old Shanghai, Shanghai People's Fine Arts Publishing House, Shanghai

Qian, Jiaju, 千家驹 1955 Archives on Chinese Public Debts, Finance and Economics Publishing House, Beijing

Rajan, Raghu and Luigi Zingales, 2001, "The Great Reversals: the Politics of Financial Development in the $20^{\text {th }}$ Century," NBER Working Paper 8178.

Riskin, Carl, 1975, "Surplus and Stagnation in Modern China," in China's Modern Economy in Historical Perspective ed. Dwight H. Perkins, Stanford University Press, Stanford.

Roll, Richard, 1972. "Interest Rates and Price Expectations during the Civil War," Journal of Economic History.

Rosenblaum, Arthur L., 1975, "Gentry Power and the Changsha Rice Riot of 1910," Journal of Asian Studies, 34(3) May, 689-715. 
Scholes, Walter V. and Marie V. Scholes, 1970, The Foreign Policies of the Taft Administration, University of Missouri Press, Columbia.

Shanghai Archive, 上海档案馆 1992, Shanghai' Stock Exchange Before the Liberation, Shanghai Document Publishing House, Shanghai

Stanley, John C., 1970, Late Ch'ing Finance: Hu Kuang-Yung as an Innovator, East Asian Research Center, Harvard University, Cambridge.

Stulz, René, 1999, "Globalization of Equity Markets and the Cost of Capital," Working Paper, Dice Center, The Ohio State University.

Sun, E-Tu Zen, 1951, “The Shanghai-Hangchow-Ningpo Railway Loan of 1908," The Far Eastern Quarterly 10(2) February, 136-150.

Sun, E-Tu Zen, 1955, "The Pattern of Railway Development in China," The Far Eastern Quarterly, 14(2) February, 179-199.

Sussman, Nathan and Yishay Yasef, 1999, "Institutions, Reforms, and country Risk: Lessons from Japanese Government Debt in the Meiji Period," Working Paper, Hebrew University.

Suzuki, Toshi, 1994, Japanese Government Loan Issues on the London Capital Market 1870-1913, Athlone Press, London.

Tauber, Rudolf, 1911, Die Börsen der Welt, Verlag für Börsen-und Finanzliterature A.-G.

Ukhov, Andrey, 2001, "Russian Government Debt Prior to 1918," Draft, International Center for Finance, Yale School of Management.

Wang, Jingyu 汪敬虞, 1999, Financial Activities of Foreign Capital in Last Century, People's Publishing House, Beijing

Willard, Kristen L. Timothy W. Guinnane, Harvey S. Rosen, 1996, “ Turning Points in the Civil War: Views from the Greenback Market," NBER Working Paper No. W5381.

Winston, A. P., 1916, "Chinese Finance Under the Republic," Quarterly Journal of Economics, 30(4) August, 738-779.

$\mathrm{Xu}$, Dixin 许涤新 and $\mathrm{Wu}$ Chengming 吴承明, 2000, Chinese Capitalism, 1522-1840, St. Martins Press, New York 
Ye, Shi-chang 叶世昌 and Pan, Lian-gui 潘连贵, 2001, Finance History of China Before the Liberation, Fudan University Publishing House, Shanghai

Zhu, Yingue, 朱荫贵, 1994, Government Interference and Modernization of China and Japan, Orient Publishing House, Beijing

Zhu, Yingue, 朱荫贵, 1998, Three Market Crashes and Shanghai Securities Market in Late 1800s and Early 1900s, China Economy History Research, Issue 3, 58-70 
表格 1 : 中国外债发行一览表

本表所列的中国政府外债情况是根据 Kulmann (1977) 和 Stanley (1970)书中的资料整理的。每项债务均以发行日期、债务种类以 及发行面值( 以当时主要的美元汇率转换为美元) 编号。债券的收益是发行时债券上标明的情况, 而不是根据发行价格确定的, 因此 往往低于债券的实际收益。币种表示债券标明的偿付货币种类。表中给出了借款目的的简要说明, 以及担保或抵押的种类。发行地表 示债券发行的地点; 多个地点则表示多次发行债券。

\section{Table 1: List of Chinese External Debt Issues}

External Debt of Chinese government as compiled from Kulmann (1977) and Stanley (1970). Each is coded by date of issue, type of debt and face value of issue, converted into U.S. Dollars at exchange rates prevailing at the time. Loan yields are as specified on the bond at issue, not market yields based upon issue price, thus they are typically a lower bound on the actual bond yield. Currency indicates the currency or form of paymen promised on the loan. The purpose of loans is briefly identified, and the type of security or collateral is listed. Place of issue indicates the location the debt was issued. Multiple locations indicate multiple bond issues.

\begin{tabular}{|c|c|c|c|c|c|c|c|}
\hline Date & Type & $\begin{array}{l}\text { US dollar amount } \\
\text { (millions) if known }\end{array}$ & Yiel & Id Currency & Purpose & $\begin{array}{l}\text { Security or collateral } \\
\text { if known }\end{array}$ & Place of Issue \\
\hline 1861 & loan & 200,000 & & tael & war & Shanghai custom voucher & \\
\hline 1862 & loan & 336,587 & 11 & tael & war & & \\
\hline 1862 & loan & 169,370 & & tael & & & \\
\hline 1864 & loan & 100,000 & 6.5 & tael & armory & & \\
\hline 1865 & loan & & & & none & none & \\
\hline 1866 & loan & & & tael & none & & \\
\hline 1866 & loan & $1,333,000$ & & tael & & $\begin{array}{l}\text { Maritime-customs/provincial } \\
\text { revenues }\end{array}$ & \\
\hline 1867 & loan & 800,000 & & tael & war & & \\
\hline 1868 & loan & $1,413,000$ & 7.25 & tael & war & & \\
\hline 1874 & loan & $3,260,000$ & 8 & sterling & war & & Hong Kong \\
\hline
\end{tabular}




\begin{tabular}{|c|c|c|c|c|c|c|c|}
\hline 1877 & bond & $3,333,000$ & 8 & tael & war & maritime customs & Hong Kong London \\
\hline 1878 & loan & $2,333,300$ & 10 & tael & war & & \\
\hline 1878 & bond & $1,667,000$ & 5.5 & tael & none & & Berlin \\
\hline 1879 & bond & & 7 & tael & none & & Hong Kong \\
\hline 1881 & loan & $2,667,700$ & 8 & tael & war & & \\
\hline 1883 & loan & 667,700 & & tael & war & & \\
\hline 1883 & loan & 667,700 & & tael & war & & \\
\hline 1884 & loan & 667,000 & 8 & tael & war & & \\
\hline 1884 & loan & 667,000 & 8 & tael & war & & \\
\hline 1884 & loan & & & sterling & armory & & \\
\hline 1885 & loan & $2,667,700$ & | & tael & war & & \\
\hline 1885 & bond & $6,543,000$ & 7 & sterling & war & maritime customs & Hong Kong London \\
\hline 1885 & loan & $6,522,000$ & 6 & sterling & rail & maritime customs & London \\
\hline 1885 & bond & $3,409,000$ & 6 & sterling & none & maritime customs & Hong Kong London \\
\hline 1886 & loan & $2,000,000$ & & tael & war & & \\
\hline 1886 & bond & 76,000 & 7 & tael & none & & Shanghai \\
\hline 1887 & loan & & 5.5 & $\mathrm{DM}$ & none & Chihli customs & Frankfort Berlin \\
\hline 1888 & loan & & 7 & tael & yellow river & & \\
\hline 1893 & loan & & & tael & none & & \\
\hline 1894 & bond & 726,000 & 7 & tael & war & maritime customs & $\begin{array}{llll}\begin{array}{l}\text { Shanghai } \\
\text { Hamburg }\end{array} & \text { Hong } & \text { Kong } & \text { Amsterdam } \\
\end{array}$ \\
\hline 1895 & bond & $4,347,000$ & 6 & sterling & indemnity & maritime customs & London \\
\hline 1895 & bond & $13,043,470$ & 6 & sterling & indemnity & maritime customs & London \\
\hline 1895 & bond & $4,347,000$ & 6 & sterling & indemnity & maritime customs & Frankfort Berlin Hamburg \\
\hline 1895 & bond & $4,347,000$ & 6 & sterling & indemnity & maritime customs & London \\
\hline 1895 & bond & $68,782,000$ & 4 & gold & none & maritime customs & $\begin{array}{l}\text { Paris St. Petersburg Geneva Brussels } \\
\text { Amsterdam Frankfort }\end{array}$ \\
\hline 1896 & bond & $69,565,000$ & 5 & gold & indemnity & maritime customs & London Berlin \\
\hline 1896 & bond & $3,333,000$ & 6 & tael & rail & Chinese Eastern Railway & Shanghai London \\
\hline 1897 & bond & $19,565,217$ & 4 & sterling & rail & $\begin{array}{l}\text { Lung-Tsing-U-Hai Railway } \\
\text { and land }\end{array}$ & Brussels \\
\hline 1898 & bond & $8,000,000$ & 5 & franc & rail & Cheng-Tai Railway & Paris \\
\hline 1898 & bond & $69,565,000$ & 4.5 & gold & indemnity & $\begin{array}{l}\text { maritime customs, salt Likin } \\
\text { revenues, customs bonds }\end{array}$ & aLondon Berlin \\
\hline
\end{tabular}




\begin{tabular}{|c|c|c|c|c|c|c|c|}
\hline 1899 & bond & $10,000,000$ & 5 & sterling & rail & Chinese Northern Railway & London \\
\hline 1899 & bond & $22,500,000$ & 5 & franc & rail & Peking-Hankow rail revenues & Paris Geneva Brussels Amsterdam \\
\hline 1900 & bond & $3,000,000$ & 5 & dollar & rail & & New York \\
\hline 1900 & bond & $1,121,739$ & 5 & sterling & cable & government guarantee & London \\
\hline 1901 & loan & & 5 & sterling & cable & & \\
\hline 1901 & bond & $300,000,000$ & 4 & sterling & indemnity & maritime custom & Shanghai \\
\hline 1903 & bond & $8,000,000$ & 5 & franc & rail & $\begin{array}{l}\text { railway and direct obligation } \\
\text { of government }\end{array}$ & Paris \\
\hline 1904 & loan & $14,772,700$ & 5 & sterling & rail & existing and future railway & London \\
\hline 1904 & $\begin{array}{l}\text { certifica } \\
\text { tes }\end{array}$ & $20,454,500$ & & sterling & rail & & \\
\hline 1904 & bond & & & sterling & rail & & \\
\hline 1904 & bond & & & dollar & war & & \\
\hline 1905 & bond & & & yen & war & & \\
\hline 1905 & loan & $4,444,000$ & 5 & sterling & indemnity & $\begin{array}{l}\text { maritime customs and } \\
\text { provincial revenues }\end{array}$ & London Berlin \\
\hline 1905 & & $4,888,800$ & & sterling & rail & $\begin{array}{l}\text { Opium revenues and internal } \\
\text { revenue bonds }\end{array}$ & London \\
\hline 1905 & loan & $8,200,000$ & 5 & franc & rail & Railway & \\
\hline 1905 & loan & & 5 & sterling & rail & \begin{tabular}{|l} 
existing railway and its \\
revenue
\end{tabular} & sLondon \\
\hline 1906 & bond & & & dollar & war & & \\
\hline 1906 & loan & & 4 & sterling & rail & & \\
\hline 1907 & loan & 400,000 & & yen & rail & & \\
\hline 1907 & bond & $6,521,700$ & 5 & sterling & rail & railway & London \\
\hline 1907 & & $4,782,600$ & 4.5 & sterling & rail & $\begin{array}{l}\text { Canton-Hankow railway and } \\
\text { its revenues }\end{array}$ & \\
\hline 1908 & bond & $6,521,000$ & 5 & sterling & rail & $\begin{array}{ll}\begin{array}{l}\text { Direct } \\
\text { government, }\end{array} \text { railway } & \text { of } \\
\end{array}$ & \\
\hline 1908 & & $1,075,000$ & 5 & yen & rail & Kirin-Changchun-railway & Tokyo \\
\hline 1908 & bond & $23,585,000$ & 5 & sterling & rail & railway & London Berlin \\
\hline 1909 & cert. & & & $\begin{array}{l}\text { chinese gold } \\
\text { dollar }\end{array}$ & war & & \\
\hline 1909 & loan & $22,727,270$ & $5(4.5)$ & sterling & rail & & \\
\hline
\end{tabular}




\begin{tabular}{|c|c|c|c|c|c|c|c|}
\hline 1909 & loan & & $5(7)$ & sterling & repay debts & $\begin{array}{|llr|}\text { provincial } & \text { likin } & \text { revenues, } \\
\text { direct } & \text { obligation } & \text { of } \\
\text { government } & & \\
\end{array}$ & \\
\hline 1909 & loan & 160,000 & 5 & yen & rail & Hsin-Feng Railway & Tokyo \\
\hline 1910 & loan & & 7 & tael & local & $\begin{array}{l}\text { guarantee of the central } \\
\text { government }\end{array}$ & \\
\hline 1910 & loan & & 7 & tael & local & Kiangnan salt revenues & \\
\hline 1910 & loan & $12,766,000$ & 5 & sterling & rail & railway and provincial revenue & London Berlin \\
\hline 1910 & loan & $2,888,510$ & 5 & sterling & rail & & \\
\hline 1911 & loan & $5,000,000$ & 5 & yen & none & $\begin{array}{l}\begin{array}{l}\text { Peking-Hankow railway } \\
\text { revenue }\end{array} \\
\end{array}$ & \\
\hline 1911 & loan & $5,000,000$ & 5 & yen & rail & $\begin{array}{l}\text { railway and revenue of } \\
\text { Kiangsu Province }\end{array}$ & \\
\hline 1911 & loan & & 7 & tael & local & $\begin{array}{l}\text { 3rd charge on the ichang salt } \\
\text { revenues }\end{array}$ & tShanghai London Paris Berlin New York \\
\hline 1911 & loan & & 7 & tael & local & $\begin{array}{l}1 \text { st charge on likin revenues of } \\
\text { Kwang-Tung }\end{array}$ & \\
\hline 1911 & loan & $2,885,000$ & 5 & sterling & armory & $\begin{array}{l}\text { salt taxes, direct obligation of } \\
\text { government }\end{array}$ & \\
\hline 1911 & loan & $39,216,000$ & 5 & sterling & rail & $\begin{array}{l}\text { revenue on general revenue } \\
\text { form Hunan and Hupeh prov. }\end{array}$ & \\
\hline 1912 & loan & $1,500,000$ & 8 & yen & rail & $\begin{array}{l}\text { revenues and stock of Kiangsi } \\
\text { railway }\end{array}$ & iTokyo \\
\hline 1912 & loan & $1,000,000$ & 8 & yen & & & \\
\hline 1912 & loan & $10,714,000$ & 5 & sterling & repay debts & & \\
\hline 1912 & loan & $1,607,100$ & 6 & sterling & rail & & \\
\hline 1912 & loan & & 7 & $\mathrm{DM}$ & local & silk likin revenues & \\
\hline 1912 & bond & & 8 & DM & local & central government guarantee & \\
\hline 1912 & bond & & 8 & tael & Treasury & $\begin{array}{l}\text { taxes of agricultural products } \\
\text { and supplementary customs } \\
\text { revenues }\end{array}$ & \\
\hline 1912 & bond & & 6 & tael & Treasury & & Shanghai \\
\hline 1912 & loan & $35,087,700$ & 5 & sterling & repay debts & $\begin{array}{l}\text { surplus of salt gabelle and } \\
\text { other government sources }\end{array}$ & London \\
\hline 1912 & loan & & 5 & DM & armory & government guarantee & \\
\hline
\end{tabular}




\begin{tabular}{|c|c|c|c|c|c|c|c|}
\hline 1913 & loan & $15,686,000$ & 5 & sterling & rail & Lung-Tsing-U-Hai Railway & Paris Brussels \\
\hline 1913 & loan & $1,765,000$ & 5 & sterling & none & $\begin{array}{l}\text { tax on transfer of property and } \\
\text { title deeds }\end{array}$ & Brussels \\
\hline 1913 & loan & $17,655,000$ & $5(6)$ & sterling & rail & & \\
\hline 1913 & loan & $19,608,000$ & 5.5 & sterling & rail & & \\
\hline 1913 & loan & $3,019,600$ & 6 & sterling & rail & & \\
\hline 1913 & loan & $98,039,200$ & 5 & sterling & repay debts & & $\begin{array}{l}\begin{array}{l}\text { London Paris St. Petersburg Brussels } \\
\text { Tokyo }\end{array} \\
\end{array}$ \\
\hline 1913 & loan & $4,706,000$ & 6 & sterling & repay debts & & London \\
\hline 1913 & loan & $7,843,100$ & 6 & sterling & none & & London \\
\hline 1914 & loan & $1,960,784$ & 6 & sterling & none & & \\
\hline 1914 & loan & $28,864,000$ & 5 & franc & $\begin{array}{l}\text { government } \\
\text { expenses/rail } \\
\text { way }\end{array}$ & $\begin{array}{l}\text { industrial enterprises it was } \\
\text { issued for,municipal taxes }\end{array}$ & $\mathrm{s}$ Paris \\
\hline 1914 & loan & $41,667,000$ & 5 & sterling & rail & \begin{tabular}{|llr} 
secured upon a second \\
mortgage & on \\
Chiaokia-Tayuan-fu railway
\end{tabular} & d London \\
\hline 1914 & loan & $1,562,000$ & 6 & sterling & repay debts & \begin{tabular}{|l} 
surplus profits of the \\
Peking-Mukden railway
\end{tabular} & Shanghai London \\
\hline 1914 & loan & 19,230 & 5 & franc & rail & & \\
\hline 1914 & bond & & 8 & $\mathrm{M}$ & Treasury & & \\
\hline 1914 & bond & $3,745,455$ & 5 & sterling & rail & & \\
\hline 1915 & loan & $2,488,000$ & 6 & yen & none & $\begin{array}{l}\text { mining concessions in Hunan } \\
\text { and Anhwei }\end{array}$ & \\
\hline 1915 & bond & $2,488,000$ & & yen & rail & 1st charge on railway & \\
\hline 1915 & bond & & & yen & war & & \\
\hline 1915 & loan & & $7(8,10)$ & franc & repay debts & & \\
\hline 1916 & bond & $1,150,000$ & 8 & dollar & rail & & \\
\hline 1916 & bond & $5,500,000$ & 8 & dollar & Treasury & & \\
\hline 1916 & loan & & 8 & tael & & & \\
\hline 1916 & loan & $5,871,400$ & 8 & sterling & repay debts & & \\
\hline 1916 & loan & 301,600 & & yen & local & & Tokyo \\
\hline 1916 & loan & $1,010,000$ & & yen & industry & & Tokyo \\
\hline 1916 & loan & 301,600 & & yen & industry & & Tokyo \\
\hline
\end{tabular}




\begin{tabular}{|c|c|c|c|c|c|c|c|}
\hline 1917 & loan & 505,000 & & yen & industry & & Tokyo \\
\hline 1917 & bond & $1,010,000$ & 6.5 & yen & local & & Tokyo \\
\hline 1917 & $\begin{array}{l}\text { certifica } \\
\text { tes(?) }\end{array}$ & $2,564,000$ & 7.5 & yen & repay debts & bank shares and treasury bonds & Tokyo \\
\hline 1917 & loan & 667,000 & & yen & local/industry & $\begin{array}{l}\text { factory and local government } \\
\text { guarantee }\end{array}$ & tTokyo \\
\hline 1917 & loan & 769,000 & & yen & local & provincial salt taxes & \\
\hline 1917 & loan & $1,179,000$ & & yen & rail & & \\
\hline 1917 & loan & & 7 & & repay debts & Bank of Bhina notes & Tokyo \\
\hline 1917 & bond & $2,122,640$ & 7 & franc & Treasury & & \\
\hline 1917 & bond & 52,173 & & taels & & & \\
\hline 1917 & loan & 272,700 & 6 & sterling & none & peking octroi & \\
\hline 1917 & loan & $1,090,900$ & 6 & sterling & none & peking octroi & \\
\hline 1917 & loan & & 7 & yen & repay debts & surplus salt revenues & \\
\hline 1917 & loan & 769,230 & & yen & local & & \\
\hline 1917 & loan & $10,256,000$ & 7.5 & yen & none & Treasury bonds & \\
\hline 1917 & & $3,333,000$ & $6(5)$ & yen & rail & $\begin{array}{l}\text { properties of railway and } \\
\text { government guarantee }\end{array}$ & \\
\hline 1917 & loan & 41,025 & & yen & local/industry & & \\
\hline 1917 & loan & 128,200 & & yen & local & & \\
\hline 1917 & loan & 25,600 & & yen & local/industry & & \\
\hline 1917 & loan & 25,600 & & yen & industry & & \\
\hline 1918 & loan & 66,200 & 9 & sterling & education & & \\
\hline 1918 & loan & & 10 & taels & none & & \\
\hline 1918 & loan & $1,052,000$ & 8 & yen & purchase & & \\
\hline 1918 & bond & 755,500 & 8 & sterling & $\begin{array}{l}\text { telecommunic } \\
\text { ation }\end{array}$ & none & \\
\hline 1918 & loan & $2,667,600$ & 8 & sterling & $\begin{array}{l}\text { army } \\
\text { equipment }\end{array}$ & $\begin{array}{l}\text { direct obligation of the } \\
\text { government }\end{array}$ & London \\
\hline 1918 & loan & 444,400 & 8 & sterling & $\begin{array}{l}\text { telecommunic } \\
\text { ation }\end{array}$ & government treasury & \\
\hline 1918 & loan & 526,000 & & yen & military & Kailan mining Adm. & Tokyo \\
\hline 1918 & loan & $5,261,000$ & 7 & yen & repay debts & surplus salt revenues & Tokyo \\
\hline 1918 & loan & $1,052,000$ & 7 & yen & local & rights to cooperate in local & 1Tokyo \\
\hline
\end{tabular}




\begin{tabular}{|c|c|c|c|c|c|c|c|}
\hline & & & & & & iron-mining & \\
\hline 1918 & loan & 526,000 & & yen & government & surplus salt revenues & Tokyo \\
\hline 1918 & loan & 526,000 & & yen & local & sundry taxes of Fukien & Tokyo \\
\hline 1918 & loan & 526,000 & & yen & industry & & Tokyo \\
\hline 1918 & loan & $7,368,000$ & 7 & yen & government & & Tokyo \\
\hline 1918 & loan & $1,052,000$ & 7 & yen & rail & revenues of the railway & Tokyo \\
\hline 1918 & loan & 52,600 & & yen & rail & & Tokyo \\
\hline 1918 & loan & $1,578,900$ & & yen & $\begin{array}{l}\text { telecommunic } \\
\text { ation }\end{array}$ & & Tokyo \\
\hline 1918 & loan & $10,521,000$ & $7.5-9$ & yen & $\begin{array}{l}\text { telecommunic } \\
\text { ation }\end{array}$ & $\begin{array}{l}\text { all telegraph properties not } \\
\text { previous pledged }\end{array}$ & tTokyo \\
\hline 1918 & loan & 526,000 & & yen & local & & Tokyo \\
\hline 1918 & loan & $10,521,000$ & 5 & yen & rail & & Tokyo \\
\hline 1918 & loan & $1,578,900$ & & yen & rail & $\begin{array}{l}\text { collieries in Fengtien owned } \\
\text { by prov. Gov. }\end{array}$ & \\
\hline 1918 & loan & $1,578,900$ & & yen & industry & & \\
\hline 1918 & loan & $5,261,000$ & & yen & repay debts & & \\
\hline 1918 & loan & $2,382,200$ & 8 & sterling & $\begin{array}{l}\text { telecommunic } \\
\text { ation }\end{array}$ & $\begin{array}{|llr|}\text { exclusive } & \text { rights } & \text { to } \\
\text { communicate } & \text { with } & \text { systems } \\
\text { outside china } & & \\
\end{array}$ & \\
\hline 1918 & loan & $5,261,000$ & 7.5 & yen & rail & & \\
\hline 1918 & loan & $15,789,000$ & 7.5 & yen & local & $\begin{array}{l}\text { Kirin and Heilongkiang gold } \\
\text { mines and government forests }\end{array}$ & \\
\hline 1918 & loan & $10,521,000$ & 8 & yen & rail & treasury bonds & \\
\hline 1918 & loan & $10,521,000$ & 8 & yen & rail & & \\
\hline 1918 & loan & $5,261,000$ & 7 & yen & & & \\
\hline 1918 & loan & $5,261,000$ & 7 & yen & & & \\
\hline 1918 & bond & & 8 & $\begin{array}{l}\text { chinese } \\
\text { dollar }\end{array}$ & industry & & \\
\hline 1918 & loan & $1,206,000$ & 10 & yen & & & \\
\hline 1918 & loan & $1,538,000$ & 7 & yen & rail & Peking-Suiyuan railway & \\
\hline 1918 & loan & $5,128,300$ & 8 & yen & $\begin{array}{l}\text { telecommunic } \\
\text { ation }\end{array}$ & $\begin{array}{l}\text { present and future gov. tel. } \\
\text { Adm. Rev. }\end{array}$ & \\
\hline 1919 & loan & 901,000 & 6 & sterling & & title deeds taxes & \\
\hline
\end{tabular}




\begin{tabular}{|c|c|c|c|c|c|c|c|}
\hline 1919 & loan & 258,500 & & yen & none & & \\
\hline 1919 & loan & 891,900 & 8 & sterling & none & & \\
\hline 1919 & loan & 572,000 & 10 & taels & none & & \\
\hline 1919 & loan & 752,000 & 9 & franc & none & & \\
\hline 1919 & loan & 76,000 & 9 & franc & none & & \\
\hline 1919 & loan & $8,122,000$ & 8 & sterling & transportation & & London \\
\hline 1919 & bond & 796,300 & 5 & franc & \begin{tabular}{|l|} 
Treasury \\
\end{tabular} & & \\
\hline 1919 & loan & 448,000 & 10.8 & taels & none & & \\
\hline 1919 & loan & 27,700 & 9 & franc & none & & \\
\hline 1919 & bond & $3,703,000$ & 7 & franc & Treasury & & \\
\hline 1919 & bond & $25,000,000$ & 6 & dollar & Treasury & wine and tobacco revenues & New York \\
\hline 1919 & loan & $5,727,000$ & 7.5 & sterling & rail & $\begin{array}{l}\text { earnings from } \\
\text { Taokow-Tchingwha railway }\end{array}$ & \\
\hline 1919 & bond & $5,500,000$ & 5.5 & dollar & Treasury & wine and tobacco revenues & New York Chicago \\
\hline 1920 & loan & & 12 & $\begin{array}{l}\text { chinese } \\
\text { dollar }\end{array}$ & repay debts & & \\
\hline 1920 & bond & $2,593,000$ & 5 & franc & none & & \\
\hline 1920 & bond & $1,075,500$ & 9 & franc & none & & \\
\hline 1920 & loan & 36,590 & 9 & sterling & education & & \\
\hline 1920 & loan & 104,070 & 8 & franc & local & & \\
\hline \multirow[t]{2}{*}{1920} & loan & 410,000 & 10.2 & yen & none & & \\
\hline & loan & 15,384 & & yen & none & & \\
\hline 1920 & loan & 70,000 & & dollar & education & & \\
\hline 1920 & loan & 60,000 & 6 & dollar & education & & \\
\hline 1920 & loan & & 8 & belgian franc & $\begin{array}{l}\text { haikow } \\
\text { harbor }\end{array}$ & LTUH railway line & Brussels \\
\hline 1920 & loan & 545,400 & 5 & sterling & rail & & \\
\hline 1920 & loan & $3,076,000$ & 9 & yen & $\begin{array}{l}\text { telecommunic } \\
\text { ation }\end{array}$ & $\begin{array}{l}\text { telegraph } \\
\text { equipment, } \\
\text { revenues }\end{array}$ & Tokyo \\
\hline 1920 & loan & & 8 & $\mathrm{Fl}$ & rail & & Amsterdam \\
\hline 1920 & loan & $1,328,000$ & 9 & yen & none & & \\
\hline 1921 & loan & & 12 & taels & Treasury & & \\
\hline 1921 & bond & 701,000 & 8 & yen & Treasury & & \\
\hline
\end{tabular}




\begin{tabular}{|c|c|c|c|c|c|c|c|}
\hline 1921 & loan & $1,718,800$ & & yen & none & & \\
\hline 1921 & loan & & 10 & sterling & none & & \\
\hline 1921 & loan & 45,100 & 10 & franc & education & & \\
\hline 1921 & loan & & 8 & belgian franc & rail & & Brussels \\
\hline 1921 & loan & 25,000 & 14 & yen & education & & Tokyo \\
\hline 1921 & loan & 28,850 & 10 & yen & education & & Tokyo \\
\hline 1921 & loan & 938,983 & 8 & dollar & none & & \\
\hline 1921 & loan & 240,000 & & yen & rail & & \\
\hline 1921 & loan & $1,442,000$ & & yen & rail & & \\
\hline 1922 & bond & $14,234,000$ & 8 & yen & repay debts & salt-surplus revenues & \\
\hline 1922 & loan & 541,000 & 15 & yen & $\begin{array}{l}\text { forestry\&mini } \\
\text { ng }\end{array}$ & & \\
\hline 1922 & loan & $3,720,000$ & 8 & sterling & rail & $\begin{array}{l}\text { projected railway from Paotow } \\
\text { to Ningshia and from Peking } \\
\text { to Paotow }\end{array}$ & London \\
\hline 1922 & bond & $6,831,000$ & 6 & yen & Treasury & $\begin{array}{l}\text { customs and salt revenues after } \\
\text { all prior claims }\end{array}$ & \\
\hline 1923 & loan & $7,121,000$ & 8 & $\begin{array}{l}\text { belgium } \\
\text { francs }\end{array}$ & rail & LTUH railway line & Brussels \\
\hline 1923 & loan & $6,870,000$ & 8 & $\mathrm{Fl}$ & rail & LTUH railway line & Amsterdam \\
\hline 1923 & bond & $19,417,000$ & 6 & yen & Treasury & $\begin{array}{l}\text { railway and government } \\
\text { guarantee }\end{array}$ & \\
\hline 1923 & loan & & 8 & taels & rail & railway & \\
\hline 1925 & bond & $43,893,900$ & 5 & dollar & indemnity & $\begin{array}{l}\text { maritime customers revenues } \\
\text { and native Chinese custom } \\
\text { revenues }\end{array}$ & Shanghai London Paris New York \\
\hline 1925 & loan & $4,340,000$ & 8 & franc & rail & LTUH railway line & Paris New York \\
\hline 1925 & loan & 21,600 & 8 & sterling & rail & $\begin{array}{l}\text { China's shared profits in } \\
\text { Shanghai-Nanking railway }\end{array}$ & \\
\hline 1925 & loan & $33,010,000$ & 8 & sterling & $\begin{array}{l}\text { reorganize } \\
\text { bonds }\end{array}$ & $\begin{array}{l}\text { taxes on transfer of property } \\
\text { and title deeds and Peking } \\
\text { octroi }\end{array}$ & \\
\hline 1928 & bond & $5,000,000$ & 6 & gold & indemnity & maritime customs revenues & Brussels \\
\hline 1928 & bond & & 8 & $\mathrm{Fl}$ & rail & & \\
\hline 1929 & bond & 757,300 & 8 & sterling & Rail & rolling stock purchased & \\
\hline
\end{tabular}




\begin{tabular}{|c|c|c|c|c|c|c|c|}
\hline 1930 & bond & $20,000,000$ & 2 & dollar & repay debts & & \\
\hline 1933 & loan & $17,105,386$ & 5 & dollar & purchase & & \\
\hline 1933 & bond & $100,000,000$ & 5.5 & dollar & treasury & & \\
\hline 1933 & bond & $4,400,000$ & 9.6 & dollar & indemnity & maritime customs & \\
\hline 1933 & Loan & $5,000,000$ & 6 & sterling & & & \\
\hline 1934 & Loan & $4,000,000$ & 6 & taels & Rail & & \\
\hline 1934 & bond & $7,352,000$ & 6 & sterling & Rail & $\begin{array}{l}\text { secured on a portion of the } \\
\text { original boxer indemnity }\end{array}$ & London \\
\hline 1934 & Loan & $5,333,000$ & 5.5 & taels & Rail & & \\
\hline 1935 & Loan & $1,172,000$ & 6 & sterling & Bridge & & \\
\hline 1935 & bond & $5,294,000$ & & yen & Rail & & Tokyo \\
\hline 1936 & loan & 750,000 & & sterling & industry & & \\
\hline 1936 & loan & $5,500,000$ & 6 & sterling & Rail & $\begin{array}{l}\text { direct obligation of the } \\
\text { government and also secured } \\
\text { on railway/bridge revenues }\end{array}$ & Shanghai \\
\hline 1936 & & $2,000,000$ & 6 & dollar & & Canton Customs & \\
\hline 1936 & & $13,500,000$ & 6 & sterling & & $\begin{array}{l}\text { Canton local tax and railway } \\
\text { income }\end{array}$ & \\
\hline 1937 & loan & & & & Rail & & \\
\hline 1937 & bond & $4,900,000$ & 4 & dollar & $\begin{array}{l}\text { reorganize } \\
\text { bonds }\end{array}$ & $\begin{array}{l}\text { direct charge on entire salt } \\
\text { revenues }\end{array}$ & \\
\hline 1937 & loan & $15,000,000$ & 5 & sterling & Rail & $\begin{array}{l}\text { surplus salt revenues not yet } \\
\text { pledged }\end{array}$ & \\
\hline 1937 & loan & $18,500,000$ & 5 & sterling & Rail & rail & \\
\hline 1937 & loan & $4,000,000$ & 6 & sterling & Rail & & \\
\hline 1937 & loan & & 6 & cgu & Rail & & \\
\hline 1937 & loan & $1,920,000$ & 6 & sterling & Rail & & \\
\hline 1937 & Loan & $50,000,000$ & 6 & dollar & & Salt tax & \\
\hline 1937 & Loan & $50,000,000$ & 6 & sterling & & Salt tax & \\
\hline 1938 & Loan & & 7 & francs & Rail & Kwangtung mining taxes & \\
\hline 1939 & Loan & $40,000,000$ & 5 & sterling & & National income & \\
\hline 1939 & Loan & $45,980,000$ & 5 & dollar & & National income & \\
\hline 1940 & Loan & $10,000,000$ & 5 & dollar & & Highway income & \\
\hline 1941 & loan & $99,800,000$ & 4 & dollar & & & \\
\hline
\end{tabular}




\begin{tabular}{|l|l|l|l|l|l|l|l|}
\hline 1945 & Loan & $400,000,000$ & 4 & dollar & & & \\
\hline 1946 & Loan & $300,000,000$ & 20 & dollar & & & \\
\hline 1982 & Loan & $40,816,000$ & 8.7 & Yen & None & & Tokyo \\
\hline
\end{tabular}


表格 2. 中国内债发行一览表

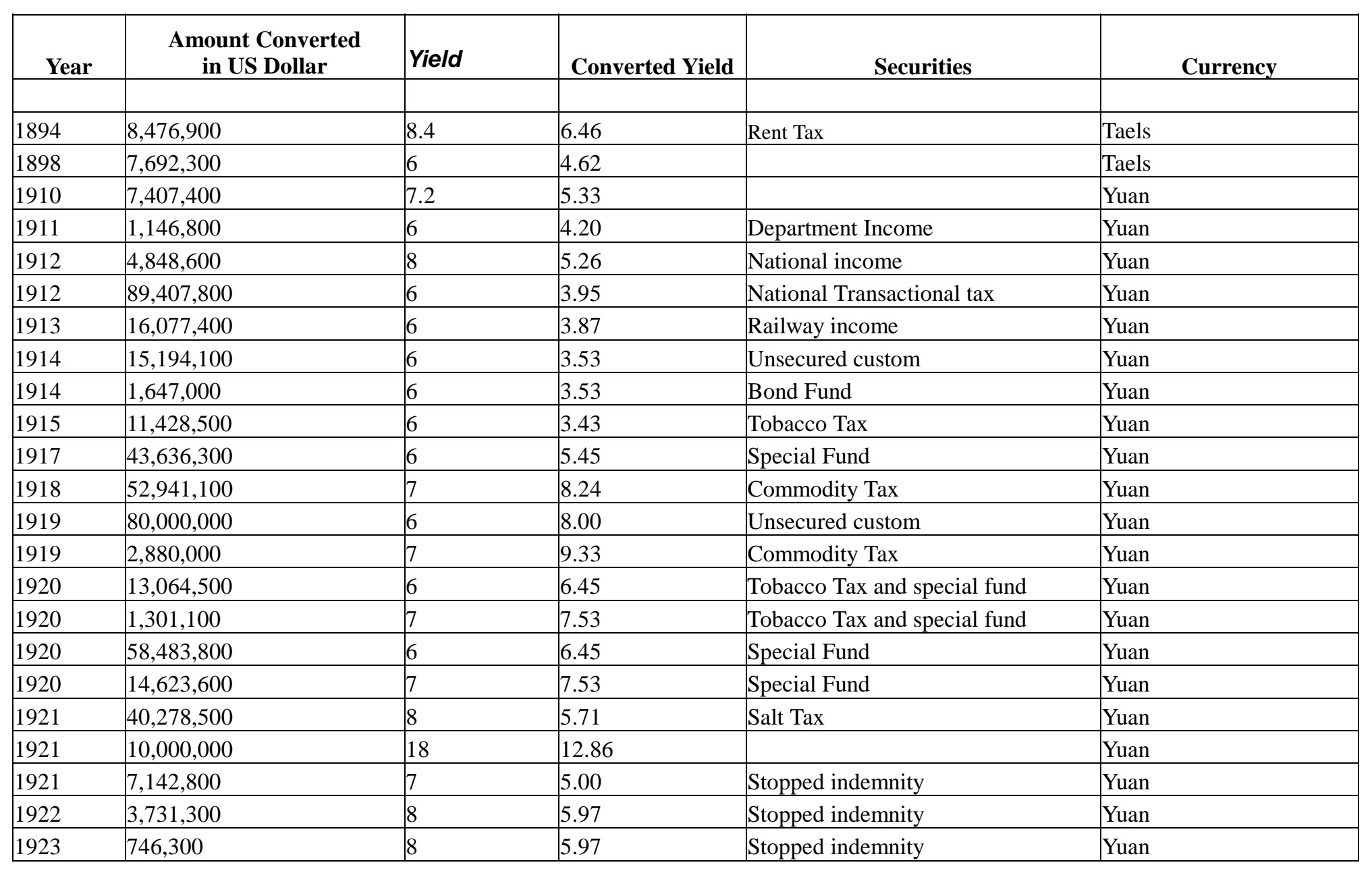




\begin{tabular}{|c|c|c|c|c|c|}
\hline 1923 & $3,134,300$ & 8 & 5.97 & Stopped indemnity & Yuan \\
\hline 1924 & $11,111,000$ & 8 & 5.93 & Stopped indemnity & Yuan \\
\hline 1924 & $5,882,300$ & 8 & 5.88 & Railway income & Yuan \\
\hline 1925 & $2,255,600$ & 8 & 6.02 & Special Fund & Yuan \\
\hline 1925 & $1,515,200$ & 8 & 6.06 & Stopped indemnity & Yuan \\
\hline 1925 & $1,818,200$ & 8 & 6.06 & Stopped indemnity & Yuan \\
\hline 1926 & & 4 & 2.72 & Hupei Export Tax & Yuan \\
\hline 1926 & $4,033,100$ & 8 & 5.30 & Hupei Export Tax & Yuan \\
\hline 1926 & $8,867,550$ & 6 & 3.97 & National Income & Yuan \\
\hline 1926 & $19,736,800$ & 7 & 4.61 & River custom & Yuan \\
\hline 1926 & $26,315,800$ & 9.6 & 6.32 & River custom & Yuan \\
\hline 1927 & & 8 & 5.00 & $\begin{array}{l}\text { National Income and transportation } \\
\text { income }\end{array}$ & Yuan \\
\hline 1927 & $18,750,000$ & 8 & 5.00 & Stopped Indemnity & Yuan \\
\hline 1927 & $28,481,000$ & 2.5 & 1.58 & Remaining customs & Yuan \\
\hline 1928 & $6,666,700$ & 8 & 5.33 & Custom Increment & Yuan \\
\hline 1928 & $31,847,100$ & 8 & 5.10 & Custom Increment & Yuan \\
\hline 1928 & $15,894,000$ & 9.6 & 6.36 & Tobacco Tax & Yuan \\
\hline 1928 & $2,649,000$ & 9.6 & 6.36 & Tianjin Custom Tax & Yuan \\
\hline 1928 & $26,143,800$ & 8.4 & 5.49 & Custom Increment & Yuan \\
\hline 1928 & $45,751,600$ & 8.4 & 5.49 & Custom Increment & Yuan \\
\hline
\end{tabular}




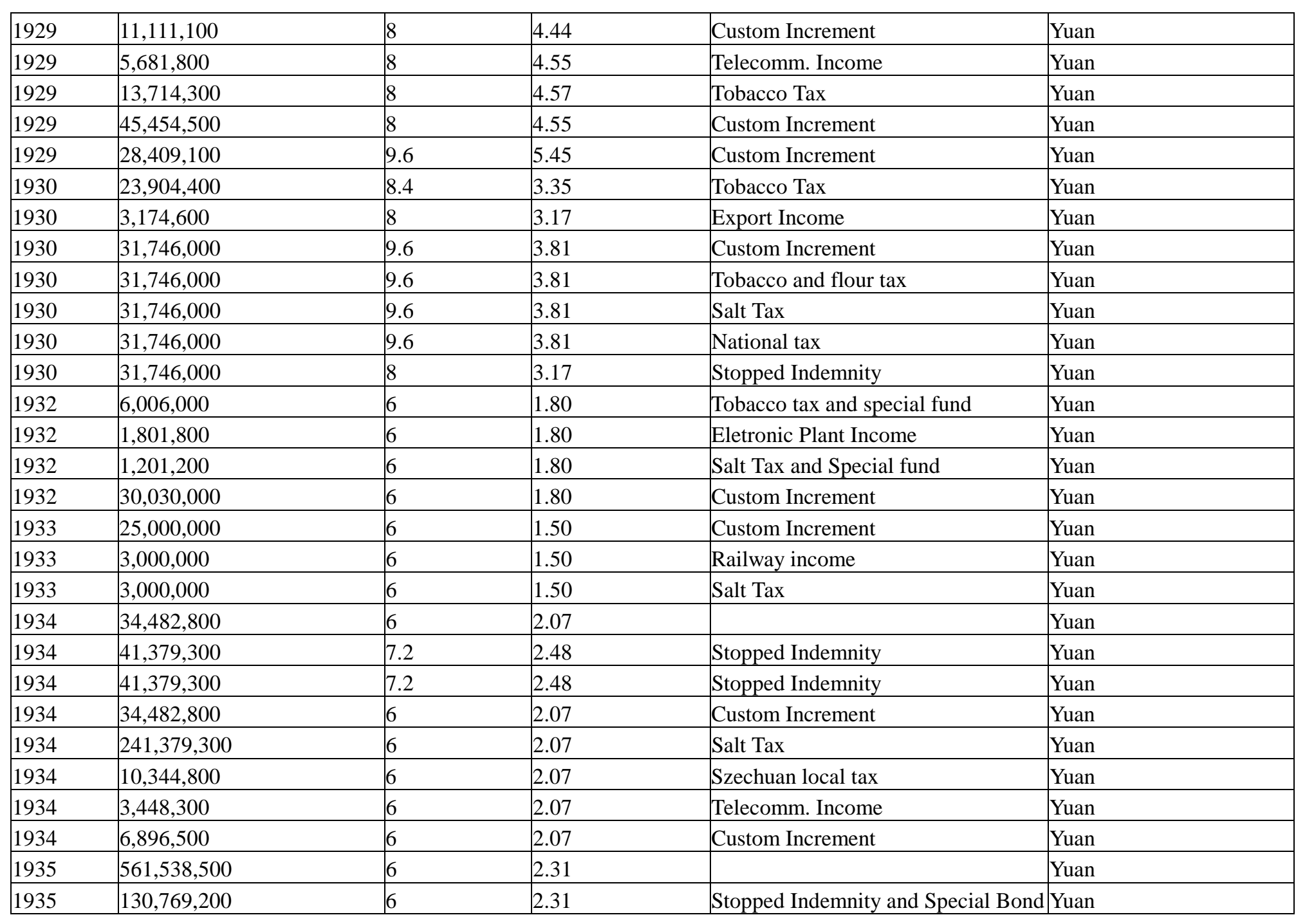




\begin{tabular}{|c|c|c|c|c|c|}
\hline 1935 & $10,384,600$ & 6 & 2.31 & Railway income & Yuan \\
\hline 1935 & $30,769,200$ & 6 & 2.31 & Railway income & Yuan \\
\hline 1935 & $5,769,200$ & 6 & 2.31 & Szechuan local tax & Yuan \\
\hline 1936 & $5,384,600$ & 6 & 2.31 & Railway income & \\
\hline 1936 & $189,230,800$ & 4 & 1.54 & National Income & Yuan \\
\hline 1936 & $6,538,500$ & 4 & 1.54 & Guang'xi Salt Tax & Yuan \\
\hline 1937 & $29,850,700$ & 5 & 1.49 & Salt tax & Yuan \\
\hline 1937 & $7,440,500$ & 4 & 1.19 & National Income & Yuan \\
\hline 1938 & $1,153,846,100$ & 6 & 1.15 & National Income & Yuan \\
\hline 1938 & $1,153,846,100$ & 6 & 1.15 & General Tax and Tobacco tax & Yuan \\
\hline 1939 & $126,161,600$ & 6 & 0.61 & National Income & Yuan \\
\hline 1941 & $5,291,000$ & 6 & 0.32 & & \\
\hline 1941 & $32,222,200$ & 6 & 0.32 & Britain loan & \\
\hline 1942 & $168,539,300$ & 6 & 0.34 & Special Fund & \\
\hline 1942 & $9,831,400$ & ] & & National income & \\
\hline 1942 & $280,898,800$ & 6 & 0.34 & National Income & \\
\hline 1945 & 204,778 & 6 & & & \\
\hline 1945 & & & & & Grain: $10,000,000$ Dan \\
\hline 1946 & & 6 & 0.00 & Foreign Exchange Fund & \\
\hline 1947 & & 15 & 0.00 & National Income & \\
\hline 1947 & & 5 & 0.00 & National Income & Jin Yuan Dollar \\
\hline
\end{tabular}


图 1.19 世纪 80 年代在中国交易的中国及外国股票价格指数

Price indices of Chinese Domestic and Foreign Stocks in 1880s

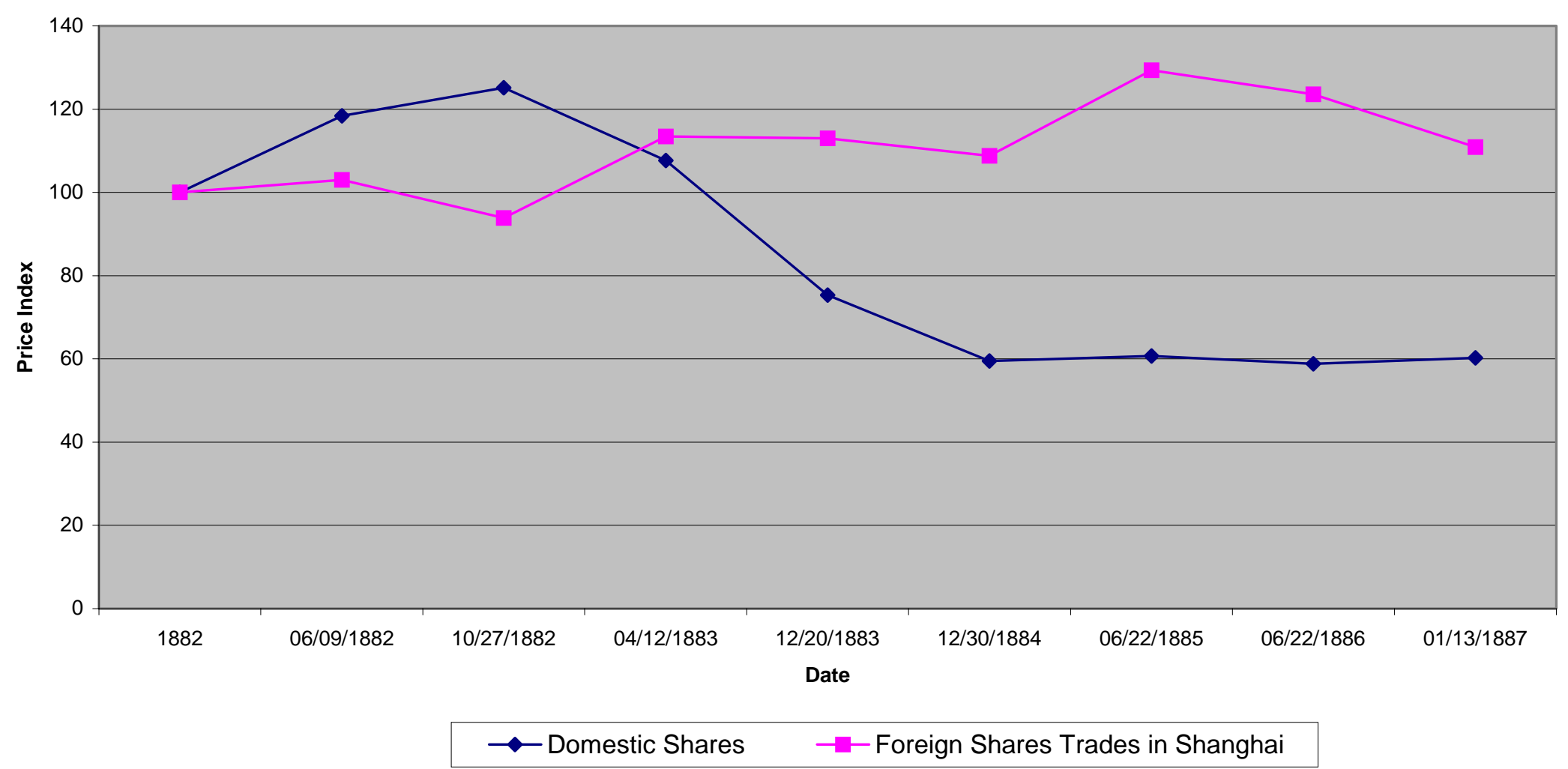


图 2. 中国, 俄国, 日本及印度的政府债券收益率

\section{Yields: China, Russia, Japan and India}

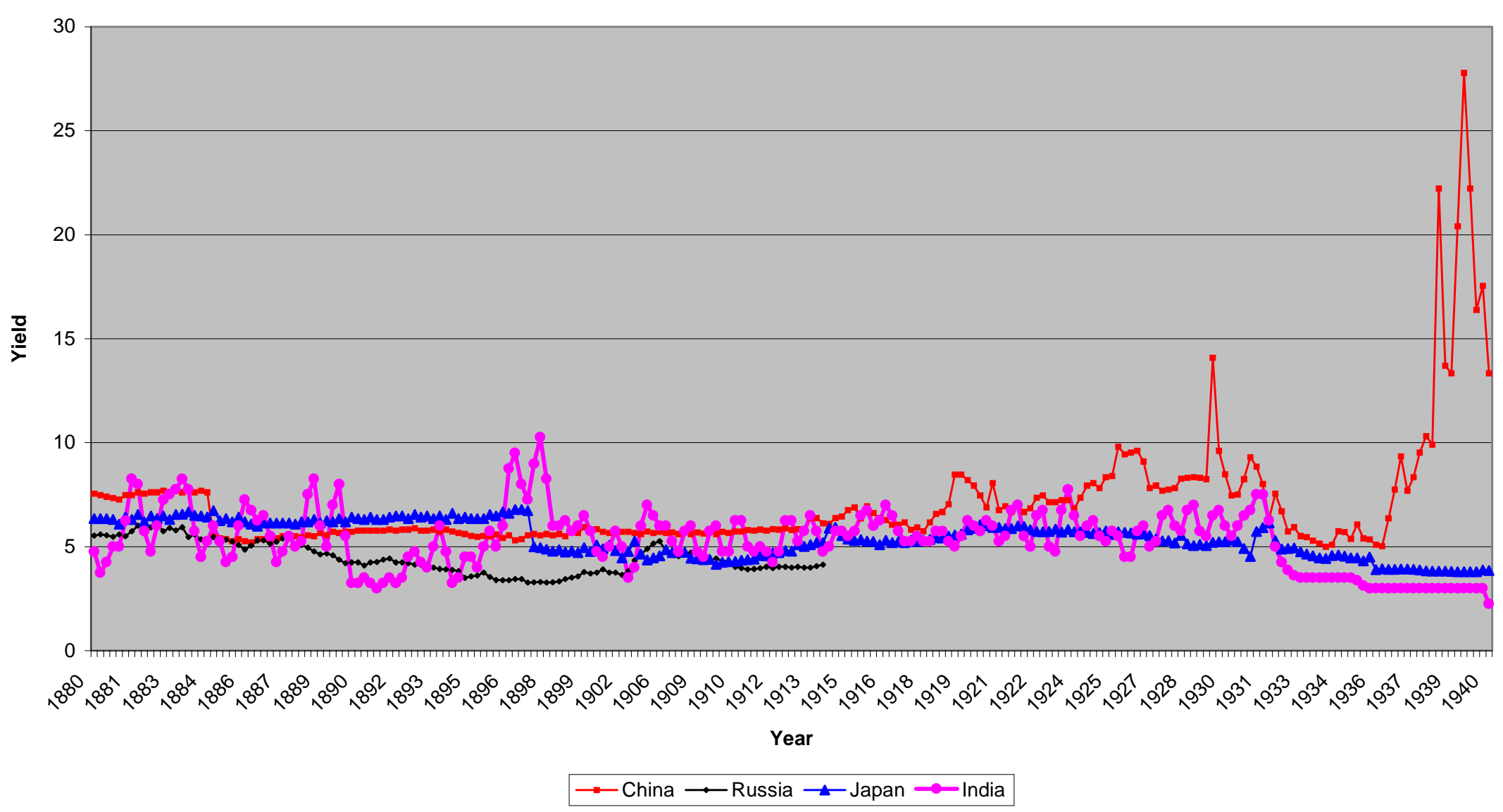


图 2. 中国, 俄国, 日本及印度的政府债券收益率 (相对于英国金边债券)

\section{Yields (Relative to British Gilt): China, Russia, Japan and India}

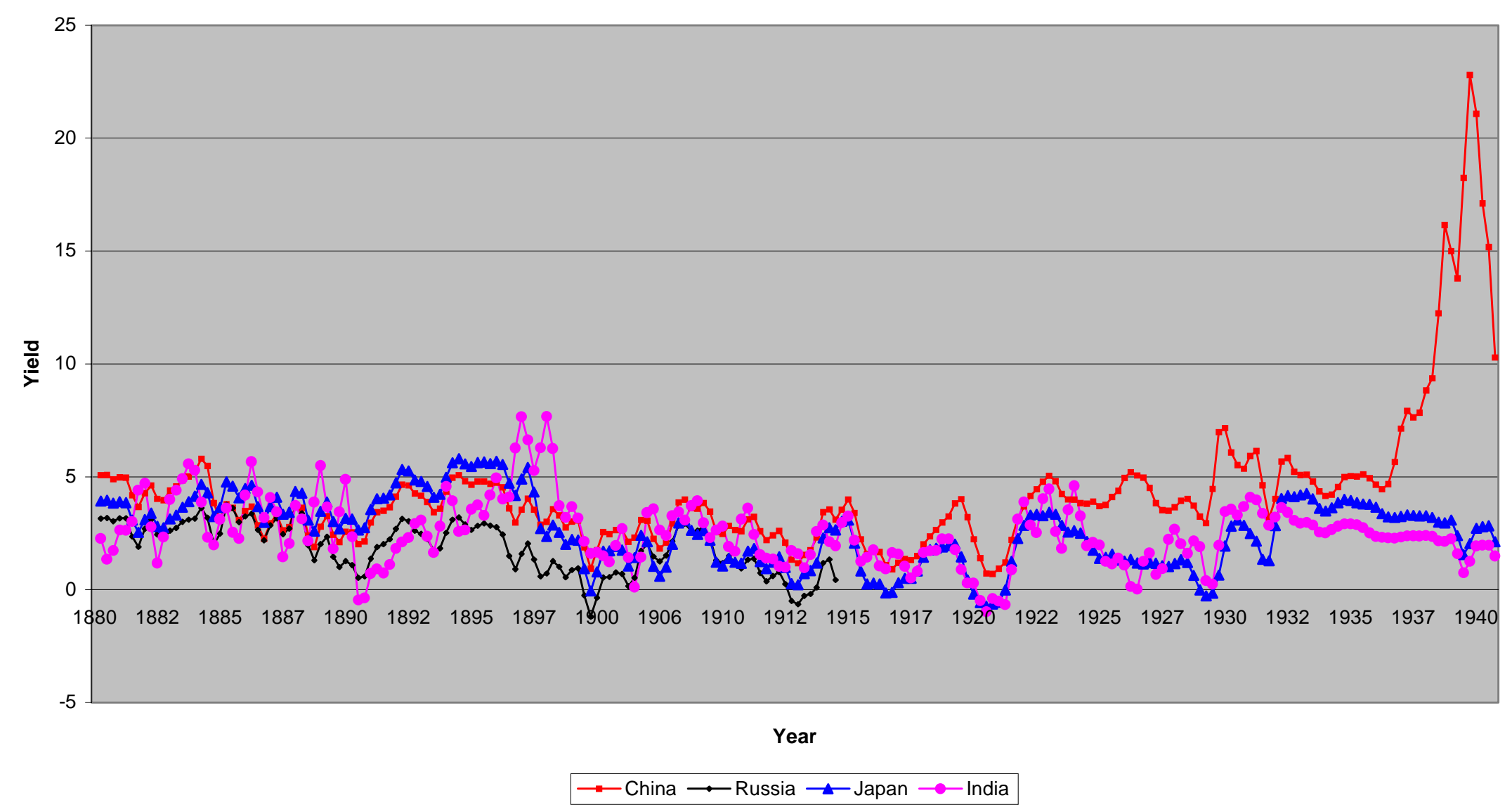

